\title{
BeATRIZ VAsconcelos
}

Estudo da freqüência de aberrações cromossômicas nos pacientes atendidos na Unidade de Genética do Instituto da Criança entre 1992 a 2002

Dissertação apresentada à Faculdade de Medicina da Universidade de São Paulo para obtenção do título de Mestre em Ciências

Área de concentração: Pediatria

Orientadora: Profa. Dra. Chong Ae Kim

SÃO PAULO

2007 
"É o trabalhador solitário o responsável pelo primeiro avanço numa pesquisa. Os detalhes podem ser testados por uma equipe, mas a primeira idéia pertence à iniciativa, ao pensamento e à percepção de um indivíduo".

(Sir Alexandre Fleming) 
A Deus, meu mestre

Que sempre coloca em meu caminho pessoas iluminadas.

Aos meus pais,

Therezinha (in memoriam.) e Rom, que, com simplicidade e amor

ensinaram-me a encarar a realidade da vida.

Ao meu querido Marco, por seu carinho e companheirismo. 


\section{AGRADECIMENTOS}

À Dra Chong Ae Kim, pelo estímulo, disponibilidade e ensinamentos.

Aos meus diletos da Genética, pela colaboração e discussão das minhas dúvidas, em especial a Dra Lílian Albano, pelos ensinamentos e seu altruísmo.

Aos professores Doutores. Durval Damiani, Lúcia Bricks e Célia Koiffmann, pelas valiosas sugestões e críticas para a qualificação deste trabalho;

À grande amiga Ivanete Sbruzzi, pela sincera amizade e apoio em muitos momentos, durante a execução deste trabalho.

À querida amiga Didi, pelo apoio na formatação desta tese.

Ao Prof. Claudinei, pela distinção e contribuição na verificação dos dados.

À Marília pela simpatia e contribuição na coleta dos dados.

À Mariza e Lurdes da Biblioteca do ICr, pelo carinho, amizade e orientação nas pesquisa bibliográficas;

À equipe do Condir, Adriana, Solange e Denise, pela ajuda atenciosa.

À equipe do apoio didático, Regina e Eduardo, pela simpatia e profissionalismo.

À Ligia e à Mara, citogeneticistas do laboratório do Instituto de Biociências, e à Dra Ângela Morgante, pela atenção e carinho com que me receberam.

Aos pacientes e seus familiares, que foram o objetivo da realização deste estudo.

A todos os familiares e amigos que estavam perto de mim, que me entusiasmaram e encorajaram nessa trajetória.

À CAPES, pela concessão da bolsa de Mestrado que possibilitou estes anos de trabalho científico. 


\section{NORMATIZAÇÃO ADOTADA}

Esta dissertação está de acordo com:

Referências: Adaptado de International Committee of Medical Journals Editors (Vancouver). Universidade de São Paulo. Faculdade de Medicina. Serviço de Biblioteca e Documentação. Guia de apresentação de dissertações, teses e monografias. Elaborado por Anneliese Carneiro da Cunha, Maria Júlia de A L Freddi, Maria F. Crestana, Marinalva de Souza Aragão, Suely Campos Cardoso, Valéria Vilhena. São Paulo: Serviço de Biblioteca e Documentação, 2004.

Abreviatura dos títulos dos periódicos de acordo com o List of Journals Indexed in Index Medicus. 


\section{SUMÁRIO}

RESUMO

SUMMARY

1 INTRODUÇÃO.............................................................................

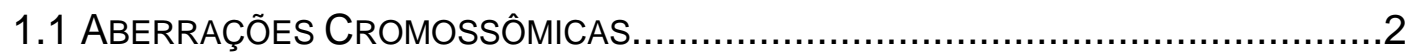

1.1.1 CLASSIFICAÇÃO DAS ABERRAÇÕES CROMOSSÔMICAS...........................3

1.1.2 ABERRAÇÕES CROMOSSÔMICAS NUMÉRICAS.....................................

1.1.3 ABERRAÇÕES CROMOSSÔMICAS ESTRUTURAIS..............................13

1.1.3.1 TIPOS DE ABERRAÇÕES CROMOSSÔMICAS ESTRUTURAIS.............14

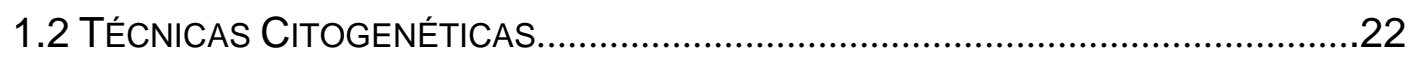

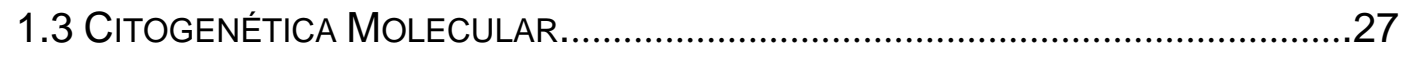

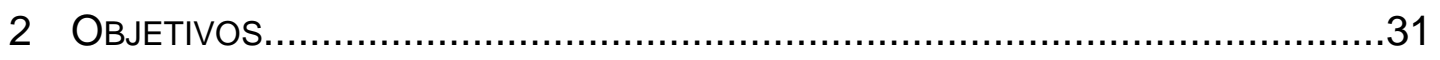

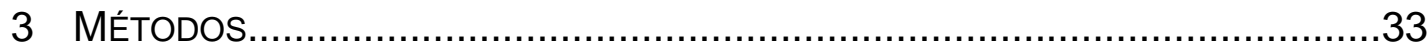

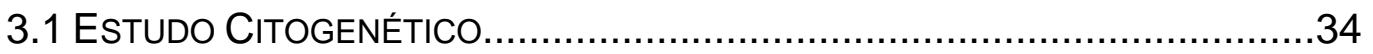

3.1.1 Técnica de Cultura Temporária de Linfócitos de Sangue PERIFÉRICO............................................................... 35

3.1.2 BANDAMENTO CROMOSSÔMICO GTG........................................36

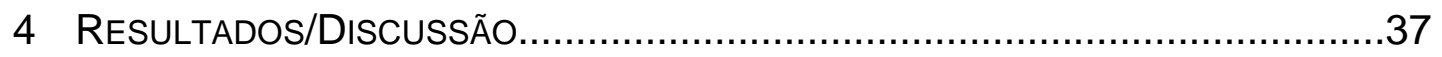

4.1 FREQÜÊNCIA DAS ABERRAÇÕES CROMOSSÔMICAS........................................38

4.1.1 TIPOS DE ABERRAÇÕES CROMOSSÔMICAS......................................39

4.1.2 ABERRAÇÕES CROMOSSÔMICAS NUMÉRICAS.................................40

4.1.3 ABERRAÇÕES CROMOSSÔMICAS ESTRUTURAIS..............................52

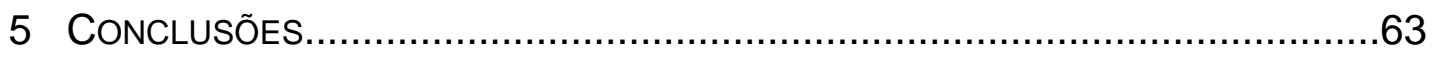

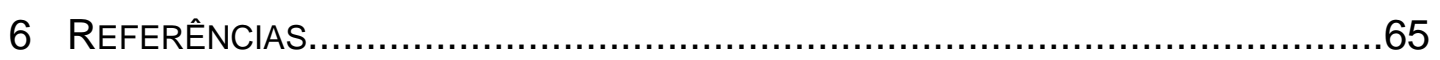




\section{LISTA DE QUADRO, GRÁFICOS E TABELAS}

Quadro 1: Incidência das principais aberrações cromossômicas observadas em nascidos vivos..

Gráfico 1: Distribuição dos cariótipos realizados no período 1992-2002.....38

Gráfico 2: Distribuição das aberrações cromossômicas encontradas em 247 propósitos no período de 1992- 2002.

Figura 1: Representação esquemática do processo do crossing over.

Figura 2: Foto de pacientes portadores das síndromes de Down, Edwards e de Patau.

Figura 3: Foto da paciente portadora de trissomia em mosaico do cromossomo 8

Figura 4: Fotos de portadores das principais aberrações sexuais encontradas nos pacientes.

Figura 5: Foto do paciente portador de três linhagens celulares e do portador de diploidia/triploidia.

Figura 6: Fotos de portadores das síndrome de "Cri-du-chat" e de WolfHirchhorn

Figura 7: Fotos de pacientes portadores de cromossomo em anel.

Tabela 1: Origem das trissomias. 9

Tabela 2: Principais aberrações cromossômicas autossômicas Encontradas.

Tabela 3: Principais aberrações cromossômicas sexuais encontradas. .48

Tabela 4: Aberrações cromossômicas estruturais identificadas nos pacientes. 


\section{LISTA DE SÍMBOLOS, SIGLAS E TABELAS}

\begin{tabular}{|c|c|}
\hline$\%$ & Porcentagem \\
\hline$<$ & Menor \\
\hline$>$ & Maior \\
\hline${ }^{\circ} \mathrm{C}$ & Graus Celsius \\
\hline pH & Potencial hidrogênio iônico \\
\hline M & Molar \\
\hline KCL & Cloreto de potássio \\
\hline ml & Mililitros \\
\hline rpm & Rotações por minuto \\
\hline DNA & Àcido desoxirribonucléico \\
\hline A & Adenina \\
\hline $\mathbf{T}$ & Timina \\
\hline C & Citosina \\
\hline G & Guanina \\
\hline $\mathbf{p}$ & Braço curto do cromossomo \\
\hline $\mathbf{q}$ & Braço longo do cromossomo \\
\hline p- & Deleção do braço curto do cromossomo \\
\hline q- & Deleção do braço longo do cromossomo \\
\hline del & Deleção \\
\hline dup & Duplicação \\
\hline $\mathbf{t}$ & Translocação \\
\hline der & Derivado \\
\hline mar & Marcador \\
\hline i & Isocromossomo \\
\hline inv & Inversão \\
\hline $\mathbf{r}$ & Anel \\
\hline add & Adição \\
\hline $\mathbf{K b}$ & Quilobase \\
\hline Mb & Megabase \\
\hline $\mathbf{n}$ & Número haplóide de uma célula (humana igual a 23) \\
\hline
\end{tabular}


2n

$3 n$

$4 n$

M

MI

MII

USG

FISH

SKY

$\mathrm{CGH}$

MLPA
Número diplóide de uma célula (humana igual a 46)

Número triplóide de uma célula (humana igual a 69)

Número tetraplóide de uma célula (humana igual a 92)

Meiose

Meiose I

Meiose II

Ultra-sonografia

Hibridação por fluorescência in situ

Cariótipo espectral

Hibridação genômica comparativa

Multiplex Ligation-dependent Probe Amplification 


\section{RESUMO}

Vasconcelos B. Estudo da freqüência de aberrações cromossômicas nos pacientes atendidos na Unidade de Genética do Instituto da Criança, entre 1992 a 2002 [Dissertação]. São Paulo: Faculdade de Medicina, Universidade de São Paulo; 2007. 72p.

INTRODUÇÃO: As aberrações cromossômicas constituem uma das maiores categorias das doenças genéticas, e são causa significativa do retardo mental e das malformações congênitas. Essas anormalidades correspondem a 50\% dos casos de abortos espontâneos, $6 \%$ de natimortos e 0,6-1\% de nativivos. OBJETIVO: Avaliar a freqüência das aberrações cromossômicas e classificar as principais aberrações encontradas nos pacientes atendidos em um serviço de Genética. CASUÍSTICA E MÉTODOS: Estudo retrospectivo de registros de resultados dos cariótipos de pacientes atendidos no Instituto da Criança no período 1992-2002. RESULTADOS: A freqüência de aberrações cromossômicas nos pacientes foi de 22\% em 1122 cariótipos. As alterações numéricas foram 70,8\% e 29,2\% estruturais. A síndrome de Down foi a aberração numérica mais encontrada em 117/247 (47,4\%) pacientes, e a segunda foi a síndrome de Edwards, em 18/247 (7,3\%), seguida pela síndrome de Patau, que ocorreu em 9/247 (3,6\%) pacientes. Entre as aberrações sexuais, a síndrome de Turner foi a mais freqüente, 18/247 $(7,3 \%)$, seguida de três casos de triplo $X$, um de Klinefelter e um duplo $\mathrm{Y}$. Dentre as aberrações estruturais, as deleções destacaram-se, com 27/247 $(10,9 \%)$ dos casos; houve nove casos de síndrome de "Cri-du-chat" e oito de Wolf-Hirschhorn. CONCLUSÃO: A freqüência significativa de aberrações cromossômicas encontradas salienta como fundamental o uso do cariótipo de rotina nos pacientes atendidos no serviço de Genética, para definição diagnóstica e aconselhamento genético aos pacientes e seus familiares.

Descritores: Aberrações cromossômicas, Citogenética, Aconselhamento genético, Genética médica/educação. 


\section{SUMMARY}

Vasconcelos B. Frequency of Chromosomal disorders in patients assisted at Instituto da Criança genetic service within the period of 1992-2002. [Dissertação]. São Paulo: Faculdade de Medicina, Universidade de São Paulo, 2007. 72p.

INTRODUCTION: Chromosomal disorders are included among the most important causes of genetic diseases with mental retardation and congenital malformation. Fifty percent of these abnormalities are spontaneously aborted and affect at least $6,0 \%$ of the stillbirth and the frequency in live births is 0.6\%-1\%. OBJECTIVE: To assess the frequency and the main of chromosomal disorders in patients assisted at a genetic service. CASUISTIC AND METHODS: A retrospective study was carried out regarding the record karyotype of patients assisted at Instituto da Criança within the period of 1992-2002. RESULTS: The frequency of chromosomal disorders of the patients was found in $22.0 \%$ among 1122 karyotypes. The numerical abnormalities among patients were $70.8 \%$ and $29.2 \%$ of them were structurals. Down syndrome was the most common numerical abnormality, found in 117/247 (47.4\%) patients, followed by Edwards syndrome in 18/247 (7.3\%) and Patau syndrome in 9/247 (3.6\%) patients. Among the sexual abnormalities, Turner syndrome was the most common, in 18/247 (7.3\%) patients, followed by three cases of triple $X$ syndrome, one case of Klinefelter syndrome and a case of XYY syndrome. Among all structural abnormalities, the deletions were the most common, found in $27 / 247$ (10.9\%) of the cases, with 9 patients with "Cri-du-chat" syndrome and 8 cases of Wolf-Hirschhorn syndrome. CONCLUSION: The significance frequency of chromosome abnormalities emphasizes the importance of the G-banding karyotyping in the routine evaluation of patients assisted at the genetic service to attain a diagnosis definition and provide genetic counseling to the patients and family members.

Descriptors: Chromosomal Disorders, Cytogenetic, Genetic Counseling, Medical Genetic/education. 
1. INTRODUÇÃO 


\subsection{ABERRAÇõEs CROMOSSÔMICAS}

O genoma humano apresenta aproximadamente cerca de 35.000 genes, que são unidades de informação genética distribuídos em locais exatos, numa molécula de DNA (ácido desoxirribonucléico), e que, em conjuntos, estão compactados em um aspecto de bastão denominado cromossomos. Os genes estão distribuídos em 23 pares de cromossomos, dos quais 22 pares são designados autossomos e dois são sexuais, $\mathrm{X}$ e Y; uma mulher normal é representada pela notação $46, X X$, e o homem, pela notação 46,XY (Nussbaum e Willard, 2004).

Os cromossomos desempenham papel relevante na transmissão da informação genética de uma geração para outra. Assim, qualquer alteração no número de cromossomos ou na seqüência de seus genes produz uma inviabilidade celular, durante a meiose, na formação dos gametas e/ou após a formação do embrião e, na maioria das vezes, resulta em anomalias ao portador, que recebem o nome de aberrações cromossômicas.

Essas aberrações também podem ocorrer durante a mitose, nas patologias do câncer, causando desequilíbrio na formação, no desenvolvimento, no crescimento e no metabolismo dessas células (Hassold e Hunt, 2001).

As aberrações cromossômicas constituem uma das maiores causas de retardo mental, déficit pôndero-estatural, dismorfismos faciais e 
malformações congênitas, tais como: cardiopatias congênitas, anomalias esqueléticas e acometimento de outros órgãos internos (OPS, 1984; Anderlid et al., 2002; Horovitz, 2005; Celep et al., 2006a; Jones, 2006).

Estima-se que $8,1 \%$ de todas as gestações reconhecidas clinicamente tenham aberrações cromossômicas, representando uma freqüência aproximada de $6 \%$ de natimortos, de $1 \%$ de nascidos vivos, e uma das principais causas de letalidade em estágios precoces do desenvolvimento fetal que leva ao aborto espontâneo em $50 \%$ dos casos (Jacobs et al., 1992b).

Em Genética Clínica, as condições indicativas para a realização da análise cromossômica são: suspeita de anormalidade cromossômica com malformações, déficit de crescimento pré e/ou pós-natal, atraso de desenvolvimento, retardo mental, dismorfismo crânio-facial, malformações congênitas, história familial com abortos recorrentes e idade materna avançada (Sharkey et al., 2005).

\subsubsection{ClassificaçÃo das AberRações Cromossômicas}

As aberrações cromossômicas são classificadas quanto ao fato de os cromossomos apresentarem perdas ou excesso de suas partes, assim como cromossomos inteiros, ou, ainda, conjuntos inteiros de cromossomos (genomas). Ainda há casos em que pode ocorrer uma mistura de linhagens celulares, com a presença de uma linhagem celular normal e outra alterada, 
evento este denominado mosaicismo.

As variações cromossômicas classificam-se em duas categorias principais: as euploidias e as aneuploidias.

As euploidias envolvem a presença do múltiplo exato do número cromossômico haplóide característico de uma espécie, constituindo séries inteiras de cromossomos ou genomas. Na espécie humana, o número haplóide é igual a 23, onde o "n" representa a metade do número diplóide de uma célula somática $(2 n=46)$, característica normal da espécie humana. No entanto, podem ocorrer as poliploidias, como a triploidia (3n) e a tetraploidia (4n), que resultam em anomalias fenotípicas (Nussbaum e Willard, 2004).

Já as aneuploidias envolvem a alteração no número cromossômico (a mais ou a menos), sem ser o múltiplo exato do número haplóide $(n=23)$. Segundo Warburton et al. (1980), no homem essas alterações cromossômicas, principalmente nos cromossomos maiores, quase sempre é letal para a célula, o que difere quanto aos cromossomos menores, como ocorre com o 21, que consegue se manter na linhagem celular, embora resulte em nascimentos com múltiplas malformações físicas e mentais.

Essas alterações cromossômicas são classificadas em dois grupos: numéricas e estruturais, afetando os cromossomos autossomos e os sexuais, ou ambos (Nussbaum e Willard, 2004). 


\subsubsection{ABERRAÇÕES CROMOSSÔMICAS NumÉRICAS}

As aberrações cromossômicas numéricas são as mais comuns, e caracterizam-se pelo número anormal de cromossomos, seja pela ocorrência de uma poliploidia, seja pela ocorrência de uma aneuploidia.

\section{o Poliploidias}

As poliploidias podem ocorrer por diferentes mecanismos; falha na meiose, no gameta feminino ou no masculino, desencadeando uma triploidia, e falha na primeira divisão do zigoto, que pode resultar numa tetraploidia. Esses eventos levam a um desequilíbrio tão grande, no genoma, que são mais freqüentemente vistos em abortos.

Um concepto totalmente triplóide, contendo 69 cromossomos, tem uma incidência de 1:10.000 nascidos vivos, mas os que resistem ao nascimento falecem logo em seguida. Estudos de polimorfismos usando análise citogenética demonstraram que a maioria dos conceptos triplóides tem origem paterna (diandria), derivados de uma dispermia (fertilização de um ovócito por um espermatozóide diplóide) (McFadden et al., 2000).

O mosaicismo diplóide/triplóide é uma condição mais rara e menos grave que a triploidia pura, na qual o afetado pode sobreviver além do período neonatal. Nesse caso, a distribuição das linhagens diplóide normal e triplóide ocorrem em graus variados, influenciando no fenótipo do portador. As conseqüências fenotípicas são: retardo mental, retardo de crescimento pré e pós-natal, sindactilia de dedos e artelhos, hipotonia e obesidade. 
Podem ocorrer, também, dismorfismos craniofaciais com fissuras palpebrais para baixo, fronte proeminente, micrognatia e depressão da ponte nasal. Podem apresentar, ainda, genitália ambígua, dependendo do complemento do sexo cromossômico das duas células presentes (Graham et al., 1981; Carakushansky et al., 1994, van de Laar et al., 2002).

Estudos cromossômicos do sangue periférico revelaram um resultado normal em $75 \%$ dos casos; assim, o diagnóstico só poderia ser definido, na maior parte dos casos, após análises de outros tecidos, como o fibroblasto. Nesse aspecto, seria possível considerar que as células diplóides levam vantagem seletiva sobre as triplóides, nos tecidos de alta renovação celular (McFadden et al., 2000; van de Laar et al., 2002).

A origem desse tipo de mosaicismo é bastante complexa, com vários mecanismos propostos. A diandria (incorporação de um espermatozóide $2 n$ num gameta feminino $n$ ) e a diginia (incorporação de um espermatozóide $n$ num gameta feminino 2n) são os mais aceitos (Dewald et al., 1975; Muller et al., 1993; van de Laar et al., 2002).

\section{O ANEUPLOIDIAS}

As aneuploidias são as aberrações numéricas mais freqüentes e clinicamente significativas encontradas no homem. Nessa classe, teremos as trissomias, quando houver três cópias de um mesmo cromossomo, ou as monossomias, quando houver apenas uma cópia, em vez de duas. Um exemplo clássico é a trissomia do 21, conhecida como síndrome de Down, e 
a monossomia do X, que é a síndrome de Turner.

\section{- INCIDÊNCIA}

A incidência das aneuploidias depende de material (sangue periférico, liquido amniótico, cordocentese e aborto) e da população estudada. Estimase que $5 \%$ de todas as concepções humanas apresentam aneuploidia. Aproximadamente $15 \%$ das gestações reconhecidas são abortadas espontaneamente, sendo que $1-2 \%$ é natimorto num estágio mais tardio de gestação, e 0,3\% compreendem os nascidos vivos (Hassold et al., 1996; Hassold e Hunt, 2001; Hall, 2006).

As trissomias mais observadas nos nascidos vivos envolvem 0 cromossomo 21, síndrome de Down, com a maior freqüência, seguido pelos cromossomos 18 e 13 e as trissomomias sexuais $(47, \mathrm{XXX}, 47, \mathrm{XXY}$ e 47,XYY) (Quadro 1) (Hassold e Chiu, 1985; Yong et al., 2003).

As trissomias são as mais identificadas nos abortos espontâneos reconhecidos clinicamente com aberração cromossômica (aquelas com morte fetal entre 6-8 semanas e 20 semanas de gestação) em $35 \%$ dos casos, aproximadamente. Entre elas, a trissomia do cromossomo 16 é a mais encontrada (33\%), e a trissomia dos cromossomos 21 e 22 correspondem a $20 \%$ dos casos. Das anormalidades envolvendo os cromossomos sexuais, a mais encontrada é a monossomia do $X(45, X)$, que aparece em 10\% dos abortos espontâneos (Jacobs e Hassold, 1987; Hassold e Hunt, 2001; Thomas et al., 2001). 
Entre os natimortos (morte fetal entre a $20^{a}$ semana até o termo), a freqüência das trissomias sobe para $4 \%$, e as mais comuns são as trissomias do 13, 18, 21 e X (Jacobs e Hassold,1987).

A incidência das principais aberrações cromossômicas observadas em nascidos vivos está descrita no Quadro 1.

Quadro 1 - Incidência das principais aberrações cromossômicas observadas em nascidos vivos

\begin{tabular}{|ll|}
\hline Tipo de aberração & Freqüência ao nascimento \\
\hline Trissomia do 21 (Síndrome de Down) & 1 em 830 \\
Trissomia do 18 (Síndrome de Edwards) & 1 em 7.500 \\
Trissomia do 13 (Síndrome de Patau) & 1 em 22.700 \\
47, XXY (Síndrome Klinefelter) & 1 em 1.000 \\
47, XYY & 1 em 1.000 \\
47, XXX & 1 em 900 \\
$45, X$ (Síndrome de Turner) & $1 \mathrm{em} 4.000$ \\
\hline
\end{tabular}

Fonte: Hsu LYF (1998) Prenatal diagnosis of chromosomal abnormalities through amniocentesis. In Milunsky A Genetic Disorders and the fetus, 4th ed. Johns Hopkins University Press, Baltimore, pp. 179-248.

\section{- ETIOLOGIA}

A aneuploidia é o evento mais comum das aberrações cromossômicas encontradas no homem, mas pouco se sabe a respeito dos mecanismos de origem, embora várias pesquisas tenham sido feitas, nesse sentido. No entanto, sabemos que as aneuploidias emergem de um erro de não-disjunção durante a meiose (M) celular I e/ou II materna, com maior freqüência durante a Ml. A não-disjunção paterna é menos comum; entretanto, existem exceções nos casos de homens com cariótipo 47, XXY, em que a origem materna e paterna está dividida igualmente (Hassold et al., 
1998; Thomas et al., 2001; Hall et al., 2006).

$\mathrm{Na}$ tabela 1 estão os resultados quanto à origem das aneuploidias encontrados por Hassold et al. (1996), num estudo com mil nascidos vivos. Nela, pode-se observar uma variação da origem parental e o estágio da meiose em que ocorre a não-disjunção dos diferentes cromossomos. Entretanto, erros na meiose materna predominam em todas as trissomias (Hassold e Hunt, 2001), pois a gametogênese feminina é um processo longo, em que a primeira divisão da meiose ocorre no período de vida prénatal e só finaliza por ocasião de cada ovulação.

Tabela 1 - Origem das trissomias

\begin{tabular}{ccccccc}
\hline & \multicolumn{6}{c}{ Origem (\%) } \\
\hline Trissomia & $\begin{array}{c}\text { Número de } \\
\text { Casos }\end{array}$ & \multicolumn{2}{c}{ Paterna } & \multicolumn{2}{c}{ Materna } & Pós- \\
& MI $^{*}$ & MII* $^{* *}$ & MI* $^{*}$ & MII* $^{*}$ & Zigótica \\
\hline $\mathbf{2}$ & 18 & 28 & - & 54 & 13 & 6 \\
$\mathbf{7}$ & 14 & - & - & 17 & 26 & 57 \\
$\mathbf{1 5}$ & 34 & - & 15 & 76 & 9 & - \\
$\mathbf{1 6}$ & 104 & - & - & 100 & - & - \\
$\mathbf{1 8}$ & 143 & - & - & 33 & 56 & 11 \\
\hline $\mathbf{2 1}$ & 642 & 3 & 5 & 65 & 23 & 3 \\
$\mathbf{2 2}$ & 38 & 3 & - & 94 & 3 & - \\
$\mathbf{X X Y}$ & 142 & 46 & - & 38 & 14 & 3 \\
\hline $\mathbf{X X X}$ & 50 & - & 6 & 60 & 16 & 18 \\
\hline
\end{tabular}

Fonte: Tabela modificada de Hassold et al., 1996. ( ${ }^{*} \mathrm{MI}$ : meiose I; ${ }^{* \star} \mathrm{MII}$ : meiose II).

\section{- Idade Materna}

Nos estudos referentes à etiologia das aneuploidias cromossômicas, com ênfase nas trissomias humanas, a idade materna avançada é um dos fatores mais pertinentes ao mecanismo de não-disjunção, o que foi 
demonstrado por Hassold e Jacobs (1984) em estudos citogenéticos de abortos espontâneos. Hassod e Chiu (1985) também demonstraram o efeito da idade materna nas trissomias, mas não encontraram relação semelhante com a monossomia do cromossomo sexual $\mathrm{X}$.

À medida que a idade materna aumenta, a taxa encontrada de trissomias é mais elevada. Há variação da porcentagem média de trissomias, de $2 \%$ nas mulheres com menos de 25 anos, para $35 \%$, nas mulheres com mais de 40 anos de idade, independentemente do cromossomo envolvido entre todas as gestações clinicamente reconhecidas (Hassold e Chiu, 1985).

Conforme Kline et al. (2000), quanto mais perto a mulher estiver da menopausa, independentemente da sua idade, maior será o risco de trissomia.

Ao nascer, a mulher carrega consigo cerca de um a dois milhões de folículos ovarianos, e só entra na menopausa quando restarem ao redor de 1000. Com o avanço da idade também há um declínio na qualidade do oócito, e isso pode manifestar-se numa fertilidade reduzida, em algumas mulheres, e em maior ocorrência de abortos, em outras.

Henderson e Edwards (1968), estudando recombinações (permuta de pequenas partes entre homólogos) em camundongos, encontraram uma redução na formação dos quiasmas (Figura 1) conforme eles envelheciam, e, quando os quiasmas ocorriam, eram mais localizados na extremidade 
cromossômica. Assim, os autores propuseram que a redução ou ausência de recombinação seria a causa da não-disjunção em mulheres em idade avançada. A importância da recombinação no processo evolutivo é indiscutível, pois a segregação independente produz novas combinações gênicas, e a seleção garante a preservação de indivíduos geneticamente adaptados.

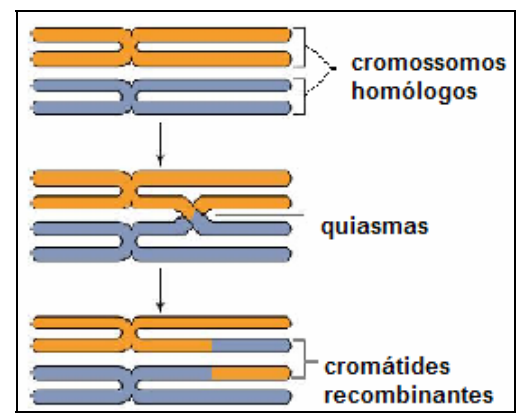

Figura 1 - Representação esquemática do processo do crossing over

Nessa fase, os cromossomos estão duplicados, e quatro cromátides estão presentes para cada par de cromossomos homólogos, formando as tétrades ou bivalentes.

Atualmente têm sido desenvolvidas pesquisas a fim de elucidar o motivo pelo qual mulheres com idade mais avançada apresentam elevada taxa de aneuploidia, em relação às mais jovens. Estudos moleculares mais recentes, corroborando com este estudo, puderam identificar em humanos que a diminuição ou falha nas recombinações cromossômicas alteram a segregação normal, ocasionando erros durante a meiose I e II. As trocas durante a recombinação, que ocorrem muito perto do centrômero ou dos telômeros, e um aumento na freqüência de recombinação na região 
pericentromérica do cromossomo parecem estar mais susceptíveis ao erro de não-disjunção.

Essas propostas vêm sendo confirmadas na gênese das trissomias humanas, e uma redução significativa na recombinação tem sido encontrada em todas as meioses I (MI) de origem materna derivadas de trissomias estudadas até hoje, incluindo as do 15, 16, 18, 21 e X (Morton et al., 1988; Lamb et al., 1996; Thomas et al., 2001).

Foram eleitos dois modelos para explicar os fatores de risco da nãodisjunção na idade materna. O primeiro, independentemente da idade materna, estaria relacionado à vulnerabilidade dos quiasmas, e o segundo, dependentemente da idade, estaria associado à vulnerabilidade dos cromossomos bivalentes na meiose I (Hassold e Sherman, 2000; Lamb et al., 2005).

Esses trabalhos demonstraram que a proporção de cromossomos susceptíveis a não-disjunção é a mesma aos 20 e 50 anos, respectivamente. Em mulheres jovens ( $<35$ anos), os mecanismos que envolvem a meiose funcionam perfeitamente, mas estão suscetíveis a falhas nos padrões de recombinação no oócito. Já nas mulheres mais velhas (>35), os mecanismos da meiose acumulam os efeitos da idade e do ambiente, tornando-se menos eficientes, e, por isso, mais propícios ao erro de não-disjunção. Assim, mesmo havendo uma recombinação eficiente, o cromossomo bivalente estaria em risco (Lamb et al., 2005). 


\subsubsection{ABERRAÇÕES CROMOSSÔMICAS ESTRUTURAIS}

Embora a maioria das doenças cromossômicas afete o cromossomo inteiro, gerando aneuploidias e alterações estruturais, também acometem os cromossomos e são relativamente comuns na população humana, com uma freqüência de $0,32 \%$, encontrada em recém-nascidos vivos estudados pelo cariótipo com bandamento G (Van Dyke et al., 1983). Os dados referentes à ocorrência dessas aberrações poderiam ser muito mais elevados, no entanto alguns desses rearranjos conferem letalidade às células, o que justifica os baixos valores encontrados em relação às aberrações numéricas (Cohen et al., 1994).

A troca de material genético entre os cromossomos homólogos (crossing over) é um fenômeno normal nas células somáticas e germinativas que asseguram a variabilidade gênica; mas, quando ocorrem erros durante esse processo, surgem alterações cromossômicas estruturais.

O estudo da correlação entre a alteração estrutural e as manifestações clínicas (estudo genótipo/fenótipo) permite obter informações importantes para o prognóstico de crianças com malformações e casais com história de abortos recorrentes ou infertilidade.

As aberrações estruturais resultam de quebras e/ou rearranjos dos cromossomos, seguidos de uma reconstituição anormal. Esse evento resultará num rearranjo estrutural equilibrado, quando não houver modificação do material genético, e, quando houver perda ou adição de 
material genético, resultará num rearranjo não-equilibrado, originando trissomia ou monossomia parcial.

Em geral, os portadores de aberrações estruturais equilibradas apresentam fenótipo normal (90-95\% dos casos), enquanto aberrações nãoequilibradas sempre desenvolvem anomalias fenotípicas (Cans et al., 1993; Jacobs et al., 1992a; Hassold e Hunt, 2001).

As quebras cromossômicas podem ser induzidas por agentes externos físicos e químicos, como a luz ultravioleta e a radiação ionizante (raios $\mathrm{X}$ ), mas também podem ser conseqüência do próprio metabolismo que ocorre normalmente nas células.

No entanto, foram selecionados, evolutivamente, mecanismos para tolerar ou reparar danos causados no material genético e, dependendo da sua reorganização, será definido o tipo do rearranjo estrutural.

Desse modo, os rearranjos apresentam diversos tipos e, teoricamente, podem acometer qualquer ponto ao longo do cromossomo envolvido. Existem, no entanto, certas regiões no genoma que têm maior suscetibilidade de ocorrência, por exemplo, nas regiões com pequenas cópias repetidas de DNA que são altamente conservadas no processo evolutivo (low copy repeats) (Shaffer e Lupski, 2000).

\subsubsection{TIPOS DE ABERRAÇÕES CROMOSSÔMICAS ESTRUTURAIS}

Os rearranjos estruturais podem envolver um ou mais cromossomos; 
quando o rearranjo ocorre no mesmo cromossomo, é classificado como intracromossomal, e, quando ocorre entre os cromossomos, como intercromossomal.

\section{o Deleção}

Deleção envolve a perda de um segmento cromossômico, resultando numa monossomia parcial, ou seja, o portador apresentará um cromossomo normal, e o seu homólogo, com deleção; portanto, a incapacidade de uma cópia única de um gene funcionar normalmente na ausência da outra cópia resultará numa haploinsuficiência. O crossing over desigual entre os cromossomos homólogos também pode ocorrer em alguns casos e resultar numa deleção. A conseqüência clínica desse evento dependerá do tamanho da região perdida e da função dos genes nela contidos.

As deleções dos cromossomos visíveis em citogenética têm uma incidência aproximada de 1:7000 nascimentos (Jones, 2006). A deleção pode ser terminal, quando as quebras ocorrerem em uma das extremidades cromossômicas, ou intersticial, se ocorrerem próximas ao centrômero. Deleções de segmentos cromossômicos distais foram descritos em todos os cromossomos, mas em geral a maioria delas parece ser única para cada indivíduo, e algumas ocorrem mais que outras. Esse predomínio em certas deleções terminais pode refletir na relativa viabilidade de monossomia para a região ou delinear uma região genômica mais propensa a rearranjos. Algumas das reconhecidas e caracterizadas são 1p-, 4p-, 5p-, 9p-, 11q-, 17q-, 18q- e 22q- (Shaffer e Lupski, 2000). 
Destacam-se as deleções do $4 p$ - e $5 p$-, que desenvolvem síndromes genéticas bem definidas, a síndrome Wolf-Hirshhorn e "Cri-du-chat", respectivamente.

\section{O ANEL}

Quando ocorrem deleções em ambas as extremidades cromossômicas, com união das partes que ficaram, surgem os cromossomos em anel. Outro mecanismo de formação considerado é uma disfunção telomérica sem perda significativa de material genético.

Os anéis são estruturas pouco comuns de serem encontradas, mas já foram descritos anéis derivados de quase todos os cromossomos humanos (Schinzel, 2001). Estima-se que ocorram em 1:25.000 conceptos reconhecidos clinicamente (Jacobs, 1992b).

Havendo na célula a presença de um cromossomo em anel extranumerário, teremos uma trissomia parcial de seqüências, e, se ele substituir um cromossomo homólogo, poderemos ter uma monossomia parcial. O cromossomo em anel é um rearranjo instável que inviabiliza a divisão celular, causando desequilíbrios diversos nas células de seus portadores.

Devido à instabilidade, o anel está sujeito a abertura, apresentando dificuldades durante as divisões celulares. Isso pode resultar em estruturas derivadas, tais como anéis parcialmente duplicados e multicêntricos, constituindo o "mosaicismo dinâmico", termo proposto por McDermott et al. 
(1977), no qual as células do portador variam quanto à estrutura e quanto ao número de anéis.

A geração de células aneuplóides, como resultado da instabilidade dos anéis, provocaria a diminuição do número de células viáveis num intervalo de proliferação qualquer. Pressupõe-se que a perda de material genético seja variável, explicando-se, assim, a grande variabilidade clínica. A síndrome do anel, proposta inicialmente por Cotè et al. (1981), predispõe seu portador a um baixo peso ao nascimento, retardo de crescimento grave, e retardo mental de leve a moderado, mas sem desvios fenotípicos significantes ou malformações maiores, e sem deleção detectável, independentemente do cromossomo considerado. Quanto maior o cromossomo envolvido na formação do anel, maior a instabilidade do anel e o retardo de crescimento no portador (Kosztolányi, 1987).

\section{O INVERSÃO}

Inversão ocorre quando um cromossomo sofre duas quebras e é reconstituído como um segmento cromossômico invertido. Podemos ter a inversão paracêntrica, se a inversão for num braço do cromossomo e distante do centrômero, ou pericêntrica, se ocorrer próximo ao centrômero. A mais recorrente no homem é a inversão pericêntrica na região de heterocromatina do cromossomo 9. É designada como heteromorfismo e considerada variação comum na população normal, na qual $2 \%$ apresenta a inversão do 9 (p11q12). Esse tipo de inversão parece não evolver manifestação no fenótipo, embora retardo mental e atraso no crescimento 
tenham sido descritos em alguns casos de inversão do 9 (Kanata et al.,1985; Krishna et al., 1992; Samonte et al., 1996).

\section{O DUPLICAÇÃo}

Duplicação ocorre quando um mesmo segmento cromossômico aparece mais de uma vez. Em geral, é menos prejudicial do que a deleção e apresenta menor manifestação fenotípica; mesmo assim, há associações entre o fenótipo e a região específica do cromossomo duplicado. Embora na literatura existam vários relatos de duplicações, o seu mecanismo de formação ainda necessita de esclarecimentos (Schinzel, 2001).

\section{o ISOCROMOSSOMO}

Isocromossomo decorre de um erro durante a divisão na meiose, havendo a duplicação de um único braço cromossômico. Já foram observados isocromossomos monocêntrico e dicêntrico, o que suporta a teoria de outro mecanismo de formação: a troca entre as cromátides irmãs.

Foram descritos isocromossomos de todos os cromossomos acrocêntricos $(13,14,15,21$ e 22). Os portadores são monossômicos para os genes do cromossomo ausente e trissômicos para os genes presentes no isocromossomo.

O isocromossomo mais comum $(1: 13.000)$ é observado na síndrome de Turner, representado pelo braço longo do cromosossomo $X(X q)$. $\mathrm{Na}$ maioria dos autossomos, os isocromossomos são letais (James et al., 1997). 


\section{O TRANSLOCAÇÃo}

Translocação é a troca de fragmentos entre dois cromossomos que sofreram quebra. Implica a remoção de um segmento cromossômico de sua posição normal para outro cromossomo, proporcionando alto risco de anomalias aos descendentes dos indivíduos portadores.

Dentre as aberrações estruturais, a translocação destaca-se com maior importância, pois é a mais freqüente observada na espécie humana (0,5\%) (Jacobs, 1992b).

As translocações equilibradas podem passar inalteradas por muitas gerações e continuarem despercebidas até os indivíduos portadores serem identificados, quando surgirem problemas reprodutivos, como abortos de repetição, natimortos ou prole com desvios fenotípicos. Esses portadores possuem graus variados de risco reprodutivo, pois durante a segregação dos cromossomos translocados na meiose poderão formar gametas anormais com trissomias ou monossomias parciais (Cohen et al., 1995).

A estimativa é que cerca de $3 \%$ dos casais com história de abortos recorrentes apresentam translocações equilibradas, e a taxa pode variar um pouco, dependendo do tipo da seleção dos casais e do exame citogenético (Fryns et al., 1998; Celep et al., 2006a).

Translocação recíproca envolve a troca de segmentos entre dois cromossomos homólogos ou não, e é observada em 1:625 indivíduos, na população. A presença de translocação recíproca aumenta os riscos de 
aparecimento de rearranjos não equilibrados de 1 até $50 \%$, na prole. Muitas translocações recíprocas são consideradas únicas, pois são relatadas apenas em indivíduos de uma mesma família. Sabe-se pouco sobre o mecanismo de formação, embora as translocações $(11 ; 22)$ (q23;q11.2) sejam comumente encontradas. Quebras no 11q e 22q são sítios comuns de rearranjos vistos em algumas síndromes (como a deleção 22q11.2, na síndrome DiGeorge/Velocardiofacial) (Edelmann et al., 1999; Shaffer e Lupski, 2000; Celep; 2006a).

Translocações Robertsonianas ocorrem entre os cromossomos acrocêntricos $(13,14,15,21$ e 22) - os braços curtos são perdidos rente ao centrômero e os braços longos dos cromossomos unem-se pelo centrômero. Essa união dos braços longos com os curtos é também denominada fusão cêntrica. Essas translocações são os rearranjos cromossômicos recorrentes mais comuns, e são encontrados em 1:1.000 indivíduos. Os portadores equilibrados possuem um cariótipo com 45 cromossomos e, em geral, sem efeito deletério no fenótipo. Isso indica que não há gene essencial nos braços curtos e que sua perda é bem tolerada (Schinzel, 2001).

Determinadas regiões dos braços curtos dos cromossomos acrocêntricos parecem conter uma afinidade em sua estrutura genômica que as predispõe à formação de translocação e recombinação. As combinações $13 q 14 q$ e $14 q 21 q$ são relativamente comuns, constituindo $85 \%$ das translocações Robertsonianas, aproximadamente. Essa afinidade entre os cromossomos 13, 14 e 21 é promovida por seqüências homólogas 
compartilhada entre eles. $O$ cromossomo 14 possui essa seqüência em orientação invertida aos braços dos 13 e 21, o que favorece as translocações. O mesmo não ocorre entre os cromossomos 13,15 e 21, cuja translocação ocorre aleatoriamente.

Em $5 \%$ dos casos de síndrome de Down, a causa é a translocação Robertsoniana, pela presença de três cópias do braço longo do 21 (Hamerton et. al., 1975; Therman et al., 1989; Shaffer e Lupski, 2000).

Inserções são translocações não recíprocas e, para sua ocorrência, é necessário que um segmento originado de um cromossomo que sofreu duas quebras num mesmo braço seja inserido, na orientação normal ou invertido, em outro cromossomo não homólogo que sofreu uma quebra. Essa alteração é um processo pouco comum; porém, quando presente, pode resultar numa prole com duplicação ou deleção, ou em portadores equilibrados.

\section{o Cromossomos marcadores}

Marcadores são cromossomos extranumerários de origem indeterminada (ISCN, 1995). O mecanismo responsável por sua formação não é conhecido. São relatados em exames de diagnóstico pré-natal, em pacientes com malformações múltiplas, em casais com infertilidade e mesmo em pacientes sem fenótipo anormal. Ocorrem numa freqüência de 0,05\%, na população, e já foram descritos em todos os cromossomos. A presença do marcador pode interferir na segregação normal dos cromossomos 
homólogos, ou na troca dos mesmos, resultando numa inviabilidade celular ou malformação na prole. A permanência de um marcador na célula também depende da sua estabilidade no processo de divisão celular, que é possibilitado pela presença do centrômero ou neocentrômero. Com as técnicas citogenéticas de bandamento em combinação com técnicas moleculares, é possível determinar a origem do cromossomo marcador (Warburton, 1991, Starke et al., 2003; Ferreira, 2005).

\subsection{TÉCNICAS CITOGENÉTICAS}

A Citogenética $($ cito $=$ célula; genética $=$ derivada da raiz grega, que significa vir a ser) surgiu como fusão da Citologia do século XIX e da Genética do século XX. O termo passou a existir a partir de 1905 , quando Bateson (biólogo Inglês) o utilizou para designar o estudo da hereditariedade e da variação dos seres vivos (Gardner e Snustad, 1986).

A partir do Congresso Mundial de Genética Humana de 1966, em Chicago - USA, os cromossomos passaram a ser classificados em sete grupos cromossômicos - A, B, C, D, E, F e G -, mas os pares de cromossomos de um grupo ainda eram bastante semelhantes. Somente a partir dos anos 70, com a descrição de novos protocolos de coloração, demonstrando um padrão único de bandas para cada par de cromossomos homólogos humanos, foi possível à distinção entre eles, conforme a distribuição das bandas ao longo dos cromossomos (ISCN, 1995). 
Durante a Conferência de Paris, em 1972, houve uma padronização na representação esquemática para classificar os 23 pares de cromossomos, designada idiograma. Atualmente, o sistema de nomenclatura é chamado An International System for Human Cytogenetics Nomenclature ISCN (ISCN, 1995).

A primeira técnica de banda - banda $Q$, foi obtida com quinacrina (Casperson et al., 1970). Hoje, essa coloração não é habitualmente usada, pois tem um tempo curto de duração e sua utilização exige microscopia de fluorescência. A classificação em grupos, a coloração dos cromossomos e a disposição conforme tamanho e posição do centrômero, (braços superiores e inferiores), permitiram a elaboração de cariótipos como método diagnóstico (ISCN, 1995; Trask, 2002).

Outros protocolos de coloração foram desenvolvidos, mas a técnica de bandas GTG se destacou como método padrão de coloração. Empregada atualmente nos laboratórios de citogenética, é comumente conhecida como banda G (Seabrigth,1970). O padrão de bandas claro e escuro é específico de cada cromossomo. As bandas escuras são regiões ricas em A-T (adenina-timina) e possuem muito poucos genes ativos, enquanto as bandas claras são ricas em C-G (citosina-guanina) e têm maior significado biológico, já que são consideradas regiões geneticamente muito ativas.

A análise dos cromossomos pela técnica do bandamento $G$, na citogenética, pelo cariótipo, é uma metodologia importante na Genética Clínica, para detecção das alterações cromossômicas numéricas e 
estruturais, ambas perfeitamente detectáveis, envolvendo os cromossomos autossomos e sexuais. Para esta pesquisa, é necessária a obtenção de células em divisão, usualmente linfócitos do sangue periférico, de medula óssea ou fibroblastos (Hamerton et al., 1975; Verma et al., 2003).

Com esse método, obtém-se um padrão de 400-550 regiões cromossômicas, ou bandas, para cada genoma haplóide. Cada uma das bandas corresponde aproximadamente, em nível molecular, a $8000 \mathrm{~Kb}$ do DNA e tem uma resolução de 3-5 megabases (Mb).

Durante muito tempo, técnicas clássicas de bandamento foram as únicas ferramentas na caracterização de muitas doenças cromossômicas associadas a malformações congênitas.

Desde a introdução das técnicas de bandamento como metodologia na pesquisa dos cromossomos humanos, a Genética Humana tem obtido notoriedade, em virtude de suas descobertas em função dos recentes avanços nas técnicas citogenéticas, e tem contribuído enormemente em todas as áreas médicas.

O prognóstico e monitoramento do tratamento são importantes áreas de atuação da Citogenética como instrumento de estudo, não apenas de geneticistas, mas também de pediatras, obstetras, neonatologistas, hematologistas, oncologistas, endocrinologistas, patologistas e psiquiatras (ISCN, 1995; Trask, 2002, Sharkey, 2005). 


\section{o Diagnóstico pré-natal}

O diagnóstico pré-natal de doenças genéticas depende da interação entre o uso dos testes de $1^{\circ}$ trimestre bioquímico (teste triplo), da ultrasonografia (USG) e dos métodos citogenéticos. Todos eles favoreceram o estudo do feto com diagnósticos cada vez mais precisos.

A dosagem de $\alpha$ - fetoproteína no sangue materno junto com a gonadotrofina coriônica e o estriol livre constitui o chamado teste triplo (realizado entre a $15^{\mathrm{a}}$ e a $20^{\mathrm{a}}$ semanas de gestação), que detecta $65 \%$ das gestações com síndrome de Down (Wald et al., 1992). O teste triplo é capaz também de rastrear outras aberrações cromossômicas, como trissomia do

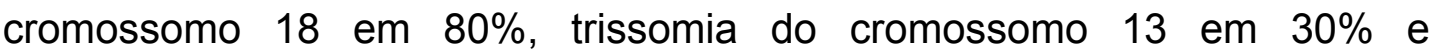
monossomia do cromossomo $X(45, X)$ em $44 \%$ dos casos. Esse teste também ajuda a rastrear $98 \%$ das gestantes com defeitos de fusão do tubo neural e $60 \%$ dos defeitos abertos da parede abdominal.

Um teste triplo "positivo" não significa necessariamente que o feto seja portador de uma aberração cromossômica. Então, após um rastreamento "positivo", deverão ser feitos exames adicionais, para determinar se há realmente uma doença, sempre com o consentimento dos pais, depois de informados sobre o exame e seus resultados.

Os exames adicionais incluem o USG (morfológico) e o estudo cromossômico pela biópsia de vilo corial, amniocentese ou cordocentese, e 
essa ordem é seguida na realização dos exames conforme o período gestacional em que foi detectada a alteração.

O diagnóstico citogenético pré-natal consiste na identificação ou exclusão de uma possível anomalia cromossômica, para estabelecer um prognóstico e permitir a interrupção dos casos pertinentes o mais precocemente possível, quando são menores os riscos maternos e os traumas psicológicos.

O exame deve ser indicado rotineiramente nas seguintes situações: mulheres acima de 35 anos; casais com filho prévio com doença cromossômica; mulheres portadoras de doenças ligadas ao X; fetos com diagnóstico na USG de malformações ou portadores de marcadores ultrasonográficos de aneuploidias (Pinto Jr., 2002; Barini et al., 2002).

A biópsia do vilo corial foi desenvolvida na década de 60 , juntamente com a amniocentese. Sua execução deve ser precoce, ou seja, entre a $11^{\mathrm{a}} \mathrm{e}$ $14^{a}$ semana da gestação (primeiro trimestre), e consiste na aspiração transabdominal de fragmentos da placenta guiada pelo ultra-som.

A amniocentese consiste na aspiração transabdominal de uma pequena quantidade de líquido amniótico da bolsa amniótica, que envolve o feto. A amostra é utilizada no cultivo de amniócitos para cariotipagem fetal (Steele e Breg 1966). A amniocentese citogenética é geralmente realizada a partir da $15^{\mathrm{a}}$ semana, mais comumente entre a $16^{\mathrm{a}}$ e a $18^{\mathrm{a}}$ semanas, e o estudo dos amniócitos está completo entre 1 e 2 semanas. O estudo pelo 
método de FISH (Fluorescent In Situ Hibridization) apresenta resultados mais rápidos, mas não é capaz de elucidar alterações como deleções ou translocações.

Em 1983, Daffos et al. descreveram a técnica da amostragem sanguínea do cordão umbilical utilizando a técnica percutânea guiada ultrasonograficamente. Todos os métodos anteriormente citados são invasivos e só ganharam espaço na obstetrícia moderna com o aumento da resolução ultra-sonográfica, que oferece menores riscos para o feto. A cordocentese é realizada preferencialmente quando há necessidade de resultados rápidos disponíveis entre 48 e 72 horas.

\subsection{Citogenética Molecular}

O grande avanço nos conhecimentos sobre Biologia Molecular, aliado à tecnologia em equipamentos laboratoriais, iniciado na década de 80 , fez evoluir as técnicas em citogenética, como as técnicas de FISH (hibridação fluorescente in situ), SKY (cariótipo espectral) e array-CGH, que é baseado na hibridização genômica comparativa. Esse avanço e a aplicação de técnicas moleculares, como as mencionadas, têm aumentado significativamente a resolução da análise cromossômica e a especificidade do diagnóstico (com sondas para regiões específicas do DNA), e permitiram a detecção de anormalidades genéticas associadas a alterações submicroscópicas até então não visualizadas. 
Essas técnicas possibilitaram esclarecimentos sobre as relações entre aberrações cromossômicas e algumas anormalidades congênitas, assim como nos estudos do genoma humano, do câncer, da evolução das espécies e também das estruturas e componentes nucleares (Trask, 2002).

A técnica de FISH baseia-se na hibridação complementar de cadeias simples de ácido nucléico ao material genético alvo fixado. Diferentes sondas estão disponíveis para o diagnóstico, permitindo identificar regiões específicas dos cromossomos (envolvendo seqüências <3Mb), como centrômeros ou um único lócus, que incluem regiões submicroscópicas, microdeleções e microduplicações.

A técnica de SKY consiste na visualização simultânea de todos os cromossomos humanos em 24 cores diferentes, e o array-CGH é baseado na hibridização genômica comparativa. São técnicas aplicadas na detecção de alterações submicroscópicas e rearranjos cromossômicos complexos.

$\mathrm{O}$ array-CGH tem sido bastante utilizado em centros diagnósticos, em virtude de sua praticidade em analisar diretamente pequenas amostras de DNA e porque pode identificar alterações com uma resolução de $1 \mathrm{Mb}$; mas também é uma técnica limitada, pois não detecta rearranjos balanceados e inversões (Trask, 2002; Gribble et al., 2005; Sharkey, 2005; Krepisch-Santos et al., 2006).

A aplicação da citogenética molecular combinada à citogenética clássica torna o diagnóstico mais eficaz, inclusive nos exames pré-natais 
(Trask, 2002; Celep, et al., 2006a, 2006b).

Hoje, a análise citogenética é um exame útil para diagnosticar vários fenótipos específicos e também para elucidar manifestações clínicas inespecíficas com alteração no crescimento e desenvolvimento (Trask, 2002; Nussbaum, 2004).

Mesmo sendo considerada uma das principais causas de morte infantil, na América Latina as doenças genéticas têm pouca atenção dos governos, que estão mais voltados aos problemas de saúde responsáveis pela morbidade e mortalidade infantil de origem socioeconômica e ambiental (OPS, 1984). No entanto, à medida que esses problemas vêm sendo resolvidos, as doenças congênitas e genéticas ganham presença no cenário brasileiro, passando de quinta para segunda causa principal de morte infantil, e, além disso, aumentam também a gravidade das intercorrências e as complicações clínicas com risco de internações (Horovitz, et al., 2005).

Apesar dessas considerações, poucos serviços de saúde executam estudos citogenéticos, ressaltando-se que, dentre as inúmeras técnicas possíveis, a metodologia da banda $G$ é imprescindível para diagnóstico etiológico, a fim de atuar no prognóstico, na prevenção e no aconselhamento genético (Santos, 2000; Horovitz, et al., 2005).

Dessa maneira, a existência de poucos estudos referentes à freqüência de aberração cromossômica, especificamente nos centros genéticos brasileiros, estimulou a realização do presente estudo, que 
objetiva avaliar a freqüência de aberrações cromossômicas em pacientes com o resultado de cariótipo, atendidos na Unidade de Genética do Instituto da Criança (ICr), de 1992 a 2002 
2. OBJETIVOS

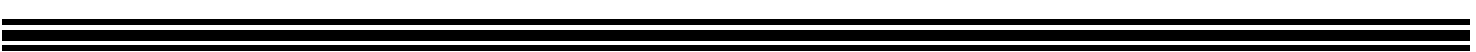


- Determinar a freqüência de aberrações cromossômicas pelo método do cariótipo, entre os pacientes atendidos na Unidade de Genética do ICr.

- Classificar e caracterizar as principais aberrações cromossômicas encontradas. 
3. MÉTODOS 
Foi realizada uma análise retrospectiva de todos os resultados de cariótipos, no período de janeiro de 1992 a dezembro de 2002, mediante análise dos registros dos pacientes atendidos no ambulatório de Genética do Instituto da Criança da Faculdade de Medicina da Universidade de São Paulo. O projeto obteve a aprovação da Comissão Ética para a Análise de Projetos de Pesquisa - CAPPesq, sob protocolo de pesquisa $n^{0}$ 177/04.

Todos os resultados de cariótipos compreendidos nesse período foram cadastrados e analisados pelo programa Microsoft Excel ${ }^{\odot}$.

O estudo cromossômico foi realizado em pacientes com retardo mental associado ou não a malformações congênitas múltiplas. Em alguns casos, o exame também foi solicitado para pais e/ou irmãos dos afetados.

A análise cromossômica foi realizada no Laboratório de Citogenética do Departamento de Genética e Biologia Evolutiva, Instituto de Biociências da Universidade de São Paulo (USP), sob supervisão da Dra. Célia P. Koiffmann. No ano de 1998, alguns exames também foram encaminhados ao Laboratório Hereditas, sob supervisão da Dra. Cleide Borovick.

\subsection{ESTUdO CITOGENÉTICO}

O estudo cromossômico é de rotina no laboratório de citogenética e consiste na cultura de linfócitos do sangue periférico, segundo o método de Moorhead et al. (1960), modificado e empregado no laboratório, com 
posterior bandamento G - usando tripsina e Giemsa (GTG), que compreende cerca de 450-550 regiões cromossômicas (Seabright, 1971). A partir daí, são diagnosticadas microscopicamente, com sucesso, as alterações cromossômicas (Swansbury, 2003).

\section{1.1 Técnica de Cultura Temporária de linfócitos de sangue periférico (Moorhead et al., 1960, modificada)}

Alíquota de 0,5 $\mathrm{ml}$ de plasma com linfócitos de sangue periférico é cultivada em 10ml de meio de cultura RPMI com L-glutamina, suplementada com fitohemaglutinina $1 \%$ e com soro fetal bovino $20 \%$, em estufa a $37^{\circ} \mathrm{C}$ por 72 horas. Trinta minutos antes de completar 72 horas, é adicionado a ela $0,1 \mathrm{ml}$ de colchicina $4 \cdot 10^{-7}$, e ela é incubada novamente a $37^{\circ} \mathrm{C}$, sendo as células bloqueadas na fase de metáfase da divisão celular. Ao término desse período, é realizada a centrifugação durante 5 minutos a $1500 \mathrm{rpm}$. O sobrenadante é descartado e são adicionados $7 \mathrm{ml}$ de solução hipotônica de $\mathrm{KCL}(0,075 \mathrm{M})$. O material fica então em banho-maria a $37^{\circ} \mathrm{C}$ por 30 minutos. Logo depois de desprezado o sobrenadante, são adicionados $2 \mathrm{ml}$ de solução fixadora (3 partes de metanol: 1 ácido acético), para bloquear a ação da solução hipotônica. Após a homogeneização, é realizada nova centrifugação por 5 minutos. Esse procedimento é repetido mais duas vezes, com banhos de $5 \mathrm{ml}$ de fixador. Ao final, o sobrenadante é removido e, a partir da suspensão celular, são preparadas lâminas contendo uma ou duas 
gotas do material, as quais são mantidas em temperatura ambiente por um período de 7 a 15 dias, para estudo citogenético, por meio das técnicas de coloração. O restante da suspensão celular é armazenado em tubos cônicos a $-20^{\circ} \mathrm{C}$

\subsubsection{Bandamento cromossômico GTG}

Para obtenção da banda G, as lâminas são incubadas em 2XSSC (cloreto de sódio $0,3 \mathrm{M}$ e citrato trissódico $0,03 \mathrm{M}$ ) por 10 minutos, a $60{ }^{\circ} \mathrm{C}$. São lavadas com água destilada e, em seguida, tratadas com tripsina 0,025\%, em tampão fosfato pH 6,8 (fosfato dissódico 0,021 M e fosfato de potássio 0,012 M) por 30 a 60 segundos. São lavadas com álcool 80\%, em seguida são coradas por 5 a 10 minutos, com Giemsa a 4\% em tampão fosfato $\mathrm{pH}=6,8$, e lavadas com água destilada e secas à temperatura ambiente. 
4. Resultado e Discussão 


\subsection{FREQÜÊNCIA DAS ABERRAÇÕES CROMOSSÔMICAS}

No período entre janeiro de 1992 e dezembro de 2002, foram analisados 1262 cariótipos; 1122 foram propósitos e 140 eram familiares. No Gráfico 1, apresenta-se a distribuição anual dos exames realizados.

\section{Gráfico 1 -Distribuição dos cariótipos realizados no período} 1992-2002

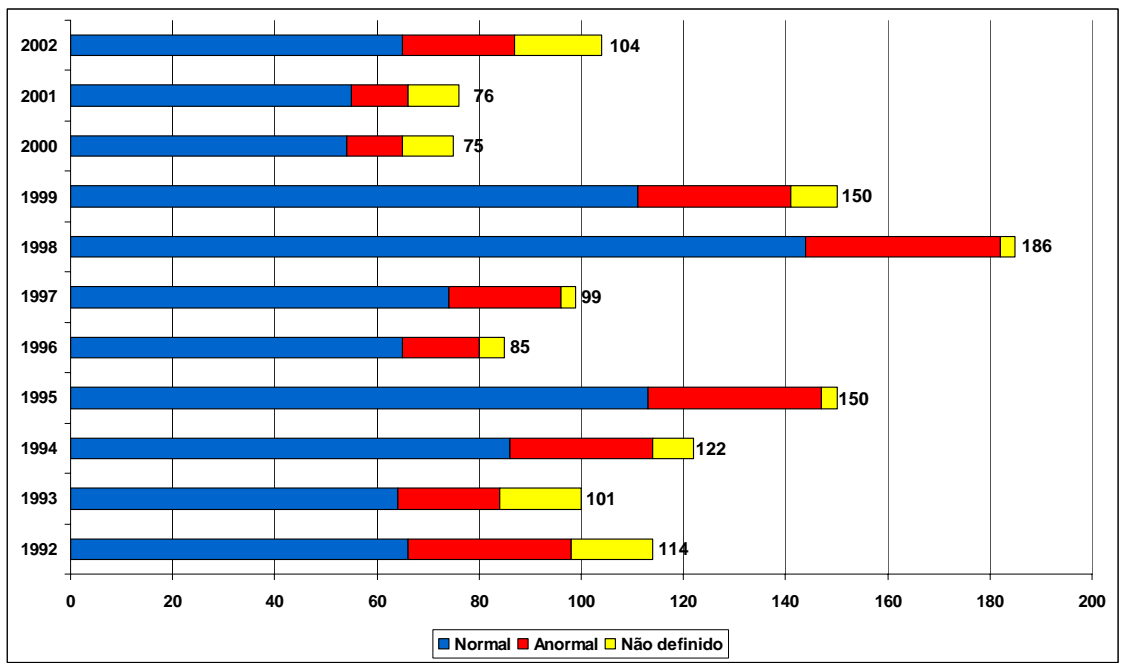

As aberrações cromossômicas foram encontradas em 265/1262 (21\%) das análises realizadas, sendo distribuídas entre 247/1122 (22\%) propósitos e 18/140 (12,8\%) nos familiares. Permaneceram com resultado não definido 71 propósitos, que continuam em estudo.

Foi possível determinar uma elevada freqüência de aberrações cromossômicas, 22\% (247/1122), nos pacientes atendidos no ambulatório de Genética do ICr.

Em outros centros de genética de diferentes estados brasileiros, a 
freqüência de aberrações cromossômicas encontrada também foi alta, e variou de 15 a 29\% (SAG-EFES, 1998; Balarin et al., 1995; Albano, 2000; Santos et al., 2000; Duarte et al., 2004). Quanto à literatura internacional, os índices de aberrações cromossômicas situam-se entre 21 e 38\% (Mokhtar 1997; El-Shanti e Al-Alami, 2002; Goud et al., 2005).

Esses valores demonstram que há uma elevada freqüência de aberrações cromossômicas nos pacientes atendidos em centros genéticos, tanto nacionais, quanto internacionais.

\subsubsection{TIPOS DE ABERRAÇõES CROMOSSÔMICAS}

As aberrações cromossômicas encontradas nos 247 propósitos corresponderam a $175 / 247(70,8 \%)$ numéricas e $72 / 247(29,2 \%)$ estruturais (Gráfico 2). As aberrações cromossômicas numéricas tiveram índice superior ao encontrado nas aberrações estruturais, variação identificada em outros trabalhos (Santos et al., 2000; Celep et al., 2006).

A maior parte das alterações - 221/247 (89,5\%) - ocorreu nos cromossomos autossômicos, enquanto 26/247 (10,5\%) ocorreram nos cromossomos sexuais, resultados estes concordantes com os da literatura (Santos et al., 2000; Duarte et al., 2004; Goud et al., 2005).

O Gráfico 2 mostra a distribuição das aberrações cromossômicas encontradas nos pacientes. 


\section{Gráfico 2 - Distribuição das aberrações cromossômicas encontradas em 247 propósitos no período de 1992-2002}

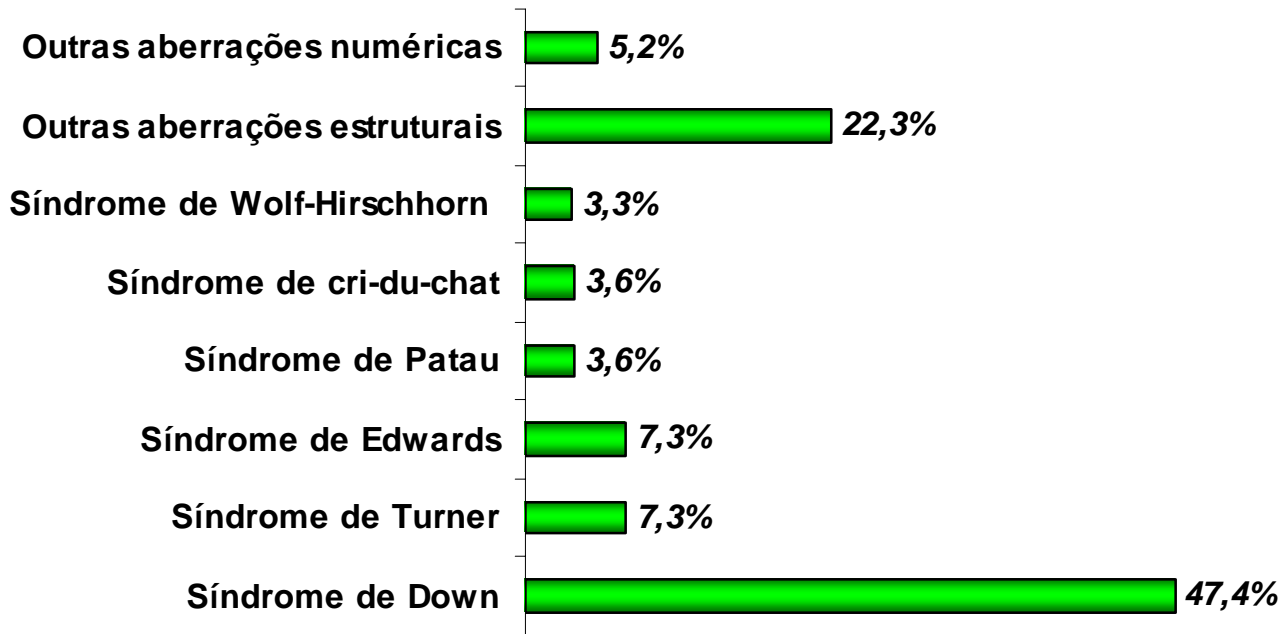

\subsubsection{AberRaÇões Cromossômicas NumÉRICAS}

\section{ANORMALIDADES AUTOSSÔMICAS}

A incidência de aberrações cromossômicas em crianças que apresentam alguma anormalidade no desenvolvimento está em torno de $15 \%$, e, dessas anomalias, as trissomias dos cromossomos autossomos $(21,18,13)$ são as mais freqüentes, representando $70 \%$ dos casos (Nazer et al., 2001).

A aberração cromossômica numérica mais freqüente no presente trabalho foi a síndrome de Down, encontrada em 117/247 (47,4\%) pacientes da casuística, e a segunda foi a síndrome de Edwards, detectada em 18/247 (7,3\%) pacientes, seguida pela síndrome de Patau, que ocorreu em 9/247 (3,6\%) pacientes (Gráfico 2). 
A síndrome de Down foi encontrada em 117 pacientes (47,4\%). Em seguida, a síndrome de Edwards, que foi detectada em 18 (7,3\%) pacientes, e Patau, em $9(3,6 \%)$ pacientes (Tabela 2). Esses dados foram concordantes com os da literatura, tanto no aspecto fenotípico (Figura 2), quanto em sua freqüência (Jones, 2006).

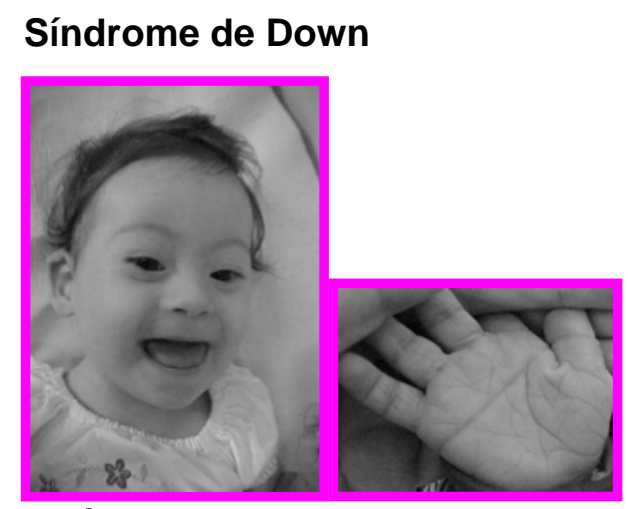

cariótipo $47, \mathrm{XX},+21$

2 anos e 1 mês

Síndrome de Edwards

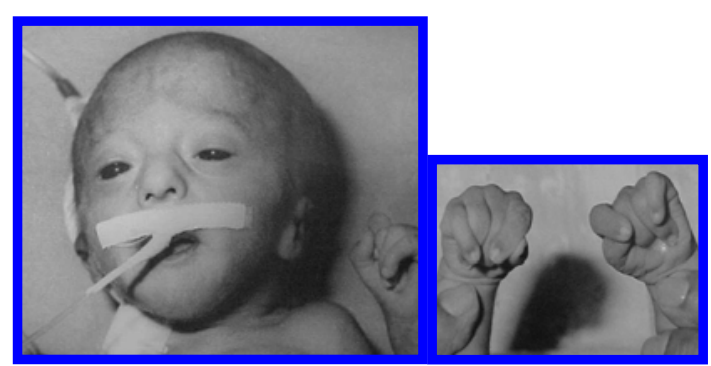

cariótipo $47, \mathrm{XY},+18$

79 dias
Síndrome de Patau

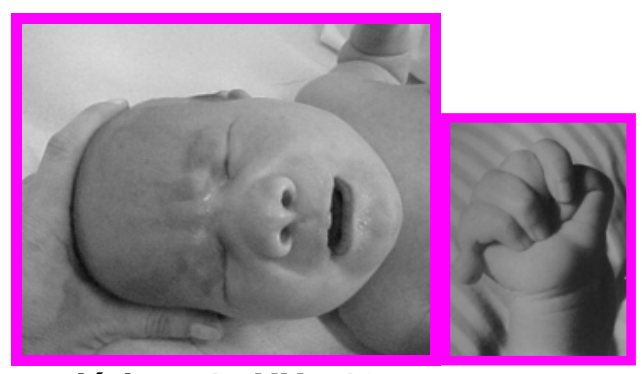

cariótipo $47, \mathrm{XX},+13$ 60 dias

Figura 2: Fotos de pacientes portadores das síndromes de Down, Edwards e de Patau

A análise do estudo cromossômico das principais trissomias autossômicas encontradas está representada na Tabela 2. 
Tabela 2 - Principais aberrações cromossômicas autossômicas encontradas

\begin{tabular}{|c|c|c|c|}
\hline Aberração cromossômica & Cariótipo & $\begin{array}{l}n^{\circ} \text { de } \\
\text { casos }\end{array}$ & Total \\
\hline \multirow[t]{7}{*}{ síndrome de Down } & $47, \mathrm{XX},+21$ ou $47, \mathrm{XY},+21$ & 104 & \multirow{7}{*}{117} \\
\hline & $46, X X,-21,+t(21 q 21 q)$ & 4 & \\
\hline & $46, X Y,-21,+t(21 q 22 q)$ & 1 & \\
\hline & $46, X X,-21,+t(21 q 20 q)$ & 2 & \\
\hline & $46, X Y, \operatorname{der}(14 ; 21)(q 10 ; q 10)+21$ & 1 & \\
\hline & $46, X X, \operatorname{der}(21 ; 22)(q 11 ; q 11)+21$ & 1 & \\
\hline & $\begin{array}{l}46, \mathrm{XX} / 47, \mathrm{XX},+21 \text { ou } \\
46, \mathrm{XY} / 47, \mathrm{XY},+21\end{array}$ & 4 & \\
\hline \multirow[t]{3}{*}{ síndrome Edwards } & $47, X X,+18$ ou $46, X Y,+18$ & 16 & \multirow{3}{*}{18} \\
\hline & $46, X Y / 47, X Y,+18$ & 1 & \\
\hline & $46, X X, t(18 p ; 21 q),+18$ & 1 & \\
\hline \multirow[t]{4}{*}{ síndrome Patau } & $47, X X,+13$ ou $47, X Y,+13$ & 5 & \multirow{4}{*}{9} \\
\hline & $46, X X / 47, X Y,+13$ & 1 & \\
\hline & $46, X X,-14, t(13 q 14 q)$ & 1 & \\
\hline & $46, X X,-13, t(13 q 13 q)$ & 2 & \\
\hline trissomia do 8 & $\begin{array}{l}46, X X / 47, X X,+8 \text { ou } \\
46, X Y / 47, X Y,+8\end{array}$ & 2 & 2 \\
\hline \multirow[t]{3}{*}{ outras trissomias } & $47, \mathrm{XY},+\mathrm{C}$ & 1 & \multirow{3}{*}{4} \\
\hline & $\begin{array}{l}46, X Y / 47, X Y+C \text { ou } \\
46, X X / 47, X X+C\end{array}$ & 2 & \\
\hline & $46, X Y / 47, X Y,+D$ & 1 & \\
\hline Total & & & 150 \\
\hline
\end{tabular}

Na síndrome de Down, o estudo cromossômico mostrou trissomia livre do 21 na maioria dos casos, 104/117 (88,9\%). As translocações ocorreram em $9 / 117(7,7 \%)$, e o mosaicismo, em $4 / 117(3,4 \%)$, mostrando a predominância de trissomia livre em relação às demais alterações cromossômicas (Tabela 2), o que também foi observado na literatura. $\mathrm{O}$ índice de translocação nos cariótipos desses pacientes foi maior, se comparado aos resultados de outros estudos.

Mokhtar et al. (1997), estudando 673 pacientes com síndrome de Down, observaram trissomia livre em $95 \%$ dos casos, translocação Robertsoniana em $2,7 \%$ e mosaico em $0,7 \%$.

Em outro estudo com um número bem maior de pacientes - 5737, 
Mutton et al. (1996) observaram índices semelhantes: 94\% de trissomia livre, $3,8 \%$ de translocação e $1,2 \%$ de mosaico.

A translocação Robertsoniana envolve os cromossomos acrocêntricos, principalmente as combinações 13q14q e 14q21q, constituindo $85 \%$ dessas translocações, aproximadamente, em razão da afinidade entre os cromossomos 13, 14 e 21, que é promovida pelas seqüências homólogas compartilhada entre eles.

Nos casos de translocação, é indicado o estudo cromossômico dos pais do paciente, já que o risco de recorrência aumenta significativamente na prole seguinte, nas translocações herdadas, o que dependerá do cromossomo envolvido e do genitor portador. Se o pai ou a mãe forem portadores da translocação $(13 q 14 q)$, os riscos para a prole é de $1 \%$, aproximadamente. Nos casos de mães portadoras da $\mathrm{t}(14 \mathrm{q} 21 \mathrm{q})$, os riscos aumentam para $10 \%$, e para $100 \%$, no caso de pai ou mãe portadores da t(21q21q) (Stene e Stengel-Ruthowski, 1998).

Já nos casos de trissomia livre, o risco foi empiricamente determinado como $1 \%$, e aumenta ainda mais, com o avanço da idade materna (Hassold et al., 1985; 1996). O mosaicismo também está relacionado à idade materna e a erros durante a divisão embrionária.

Na síndrome de Edwards, a trissomia livre foi encontrada em 16/18 $(88,9 \%)$ casos, $1 / 18$ com translocação e 1/18 com mosaicismo, representando $5,5 \%$ dos casos, cada. 
Na síndrome de Edwards, o risco de recorrência, independentemente da alteração cromossômica, é inferior a $1 \%$, enquanto nos casos de translocação sobe para 5\% (Bugge et al., 1995; Schinzel, 2001).

Dados da literatura referem que, apesar de diferentes alterações genotípicas envolvendo o cromossomo 18 resultarem no fenótipo da síndrome de Edwards, porém com expressividade variável, a trissomia livre aparece na grande maioria dos casos (90 a 94\% dos casos) (Bugge et al., 1995; Jones, 2006).

Na síndrome de Patau, a trissomia livre foi encontrada em 5/9 (55,5\%) casos; a translocação, em 3/9 (33,3\%); e, o mosaicismo, em 1/9 (11,1\%). Nessa síndrome, o risco de recorrência por trissomia livre é inferior a 1\%, e é desprezível. Nos casos de translocação, o estudo dos pais é indicado; no entanto, diferentemente das outras trissomias, mesmo havendo a herança parental, a recidiva é inferior a 1\%, provavelmente em razão da incidência de abortos.

Conforme a literatura, a trissomia do 13 é menos freqüente que a do 18 e a do 21. A grande maioria dos conceptos com trissomias morre durante o período embrionário, nos primeiros meses, e a sobrevida até o segundo trimestre é de 5\% (Zoll et al., 1993; Sugayama et al., 1999; Schinzel, 2001).

Com relação às síndromes de Edwards e Patau, a maioria dos afetados é abortada espontaneamente, entretanto alguns chegam a nascer com um fenótipo bem característico, com sobrevida mais curta. No entanto, 
existe uma possibilidade muito remota, mas não insignificante, de uma criança ter uma sobrevida relativamente longa, especialmente se não forem detectadas malformações cardíacas e cerebrais graves. Nesse caso, o tempo de sobrevida depende, em parte, dos achados citogenéticos presentes (trissomia livre do 13 ou mosaicismo de trissomia do 13) e, em parte, das malformações graves (Zoll et al., 1993). Há também estudos que relatam que pacientes com translocação Robertsoniana sobrevivem mais do que pacientes com trissomia livre do 13 (Redheendran et al.,1981;Giaccardi et al., 1991; Sugayama et al., 1999).

Existem alguns trabalhos de sobrevida prolongada, como 0 levantamento de 20 anos realizado no ambulatório da Unidade de Genética do ICr (Sugayama et al., 1999), que estudou 24 pacientes com síndrome de Edwards e 20 com síndrome de Patau, e a sobrevida média de cada um deles foi de 54,6 e 35,3 dias, respectivamente.

Dois casos de síndrome de Edwards de nossa casuística também apresentaram sobrevida prolongada; uma menina com trissomia livre, que faleceu aos 11 anos de idade, e um menino de dois anos, com cariótipo em mosaico e com fenótipo parcial para a síndrome. Ambos os casos evoluíram com hipotonia, dificuldade do desenvolvimento e atraso de desenvolvimento neuropsicomotor. Provavelmente o manejo terapêutico adequado e o tratamento multidisciplinar precoce também podem ter contribuído para o tempo de vida prolongado desses pacientes.

A trissomia do 8 em mosaico foi observada em apenas dois pacientes 
(um menino e uma menina), com quadro clínico semelhante ao relatado anteriormente (Jones, 2006). A menina (Figura 3) apresentava: retardo mental, microcefalia com desproporção crânio-face, fendas palpebrais com inclinação para cima, narinas antevertidas, filtro hipoplásico, dentes incisivos espaçados, orelhas assimétricas e proeminentes, escoliose, espinha bífida, tórax estreito e comprido, clinodactilia do $5^{\circ}$ dedo, sulcos palmares bem marcados, hálux valgo com sulcos plantares bem marcados e cardiopatia congênita. O menino, além das características em comum com a menina, apresentava também coxas valgas, criptorquia com hipospádia.

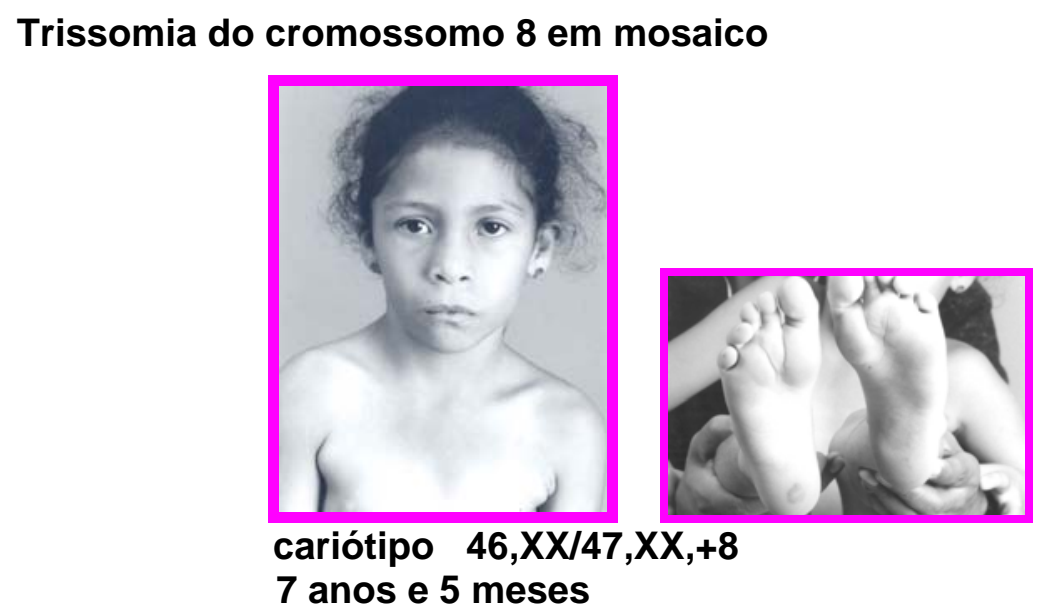

Figura 3: Foto da paciente portadora de trissomia em mosaico do cromossomo 8.

\section{ANORMALIDADES SEXUAIS}

Com uma incidência de 1:400 dos nascidos vivos, nas anormalidades sexuais é observado um alto índice de dificuldade no aprendizado e na linguagem, desvios de comportamento, alteração hormonal e nos caracteres sexuais secundários (Linden e Bender, 2002). 
As alterações envolvendo os cromossomos sexuais representaram 26/247 (10,5\%) de nossa casuística. A Síndrome de Turner foi a mais freqüente, encontrada em 18/247 (7,3\%) pacientes, seguida de três casos de triplo X, um de Klinefelter e um duplo Y (Figura 4) (Tabela 3).

As principais aberrações cromossômicas sexuais encontradas nos pacientes estão representadas na Figura 4 e na Tabela 3.

Síndrome de Turner

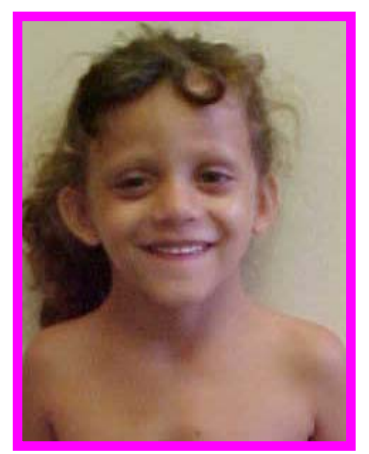

cariótipo $45, X$ 5 anos e 1 mês triplo $\mathrm{X}$

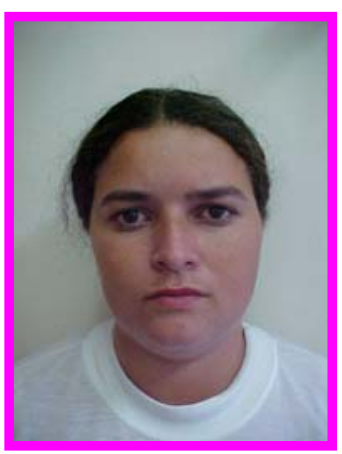

cariótipo $47, \mathrm{XXX}$ 24 anos triplo $X$

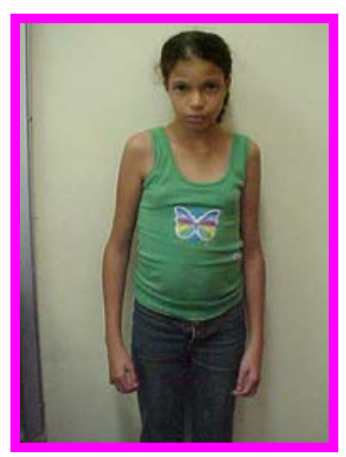

cariótipo 47,XXX 12 anos
Síndrome de Klinefelter

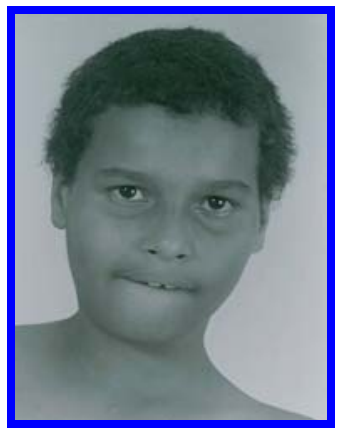

cariótipo $47, \mathrm{XXY}$

11 anos
Síndrome do duplo Y

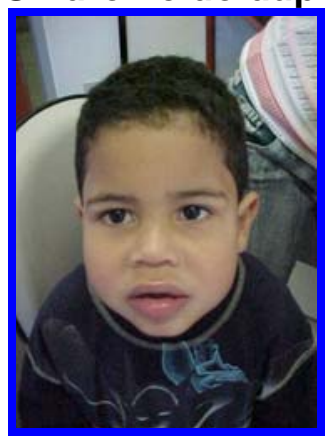

cariótipo $47, \mathrm{XYY}$

4 anos e 7 meses

Figura 4: Fotos de portadores das principais aberrações sexuais encontradas nos pacientes. 
Tabela 3 - Principais aberrações cromossômicas sexuais encontradas

\begin{tabular}{llcl}
\hline Aberração cromossômica & \multicolumn{1}{c}{ Cariótipo } & $\begin{array}{c}\mathbf{n}^{\circ} \mathbf{d e}^{\mathbf{*}} \\
\text { casos }\end{array}$ & \% $^{* *}$ \\
\hline Síndrome deTurner & $45, \mathrm{X}$, & 9 & 3,6 \\
& $45, \mathrm{X} / 46, \mathrm{XX}$ & 5 & 2,0 \\
& $45, \mathrm{X} / 45, \mathrm{X}+\mathrm{mar} ;$ & 1 & 0,4 \\
& $46, \mathrm{X} / \mathrm{Xi}(\mathrm{Xq})$ & 1 & 0,4 \\
& $45, \mathrm{X} / 46, \mathrm{Xi}(\mathrm{Yq})$ & 1 & 0,4 \\
& $46, \mathrm{X}, \mathrm{der}(\mathrm{X}) \mathrm{t}(\mathrm{X}: \mathrm{Y})(\mathrm{p} 22 ; \mathrm{q} 11)$ & 1 & 0,4 \\
\hline Síndrome do triplo $\mathrm{X}$ & $47, \mathrm{XXX}$ & 3 & 1,2 \\
Síndrome de Klinefelter & $47, \mathrm{XYY}$ & 1 & 0,4 \\
Síndrome do duplo $\mathrm{Y}$ & $47, \mathrm{XXY}$ & 1 & 0,4 \\
Três linhagens celulares & $45, \mathrm{X} / 46, \mathrm{XY} / 46, \mathrm{Xi}(\mathrm{Y})$ & 1 & 0,4 \\
Diploidia/triploidia & $46, \mathrm{XY} / 69, \mathrm{XXY}$ & 1 & 0,4 \\
Translocação do $\mathrm{X} / 6$ & $46, \mathrm{X} / 6$ & 1 & 0,4 \\
\hline \multicolumn{1}{c}{ Total } & & $\mathbf{2 6}$ & $\mathbf{1 0 , 5}$ \\
\hline "no: número; \%: percentual & & &
\end{tabular}

Entre os casos de síndrome de Turner (7,3\%), o cariótipo clássico 45,X foi o mais encontrado, em $9 / 18(50,0 \%)$ dos casos, seguido de mosaicismo em $5 / 18(27,7 \%)$, e de outras alterações estruturais em 4/18 $(22,2 \%)$ (Tabela 3). Cerca de $60 \%$ dos casos da literatura apresentam o cariótipo 45,X, enquanto os restantes são mosaicos ou estruturais (Lippe, 1991).

Foram observadas 16/18 pacientes com dismorfismos típicos para a síndrome, enquanto 2/18 pacientes $(45, X / 46, X X$ e $46, X$ del $X p)$ apresentaram fácies normal; no entanto, todas elas apresentaram baixa estatura. Das meninas que entraram na adolescência (6/18), todas tiveram amenorréia primária, e a paciente com mosaicismo 45,X/46,Xi(Yq) apresentou genitália ambígua. Cinco pacientes apresentaram cardiopatia congênita, duas manifestaram anomalia renal, uma, Diabets insipidus, e uma outra, hipotireoidismo. 
O fenótipo é variável na síndrome de Turner, mesmo em pacientes não mosaicos. A razão para isso não é clara, mas alguns trabalhos estudam a influência da origem parental (paterna ou materna) do único cromossomo X existente nessas pacientes (Larsen et al., 1995, Jacob, et al., 1997).

O triplo $X$ ou $47, X X X$ foi encontrado em $3 / 247$ pacientes $(1,2 \%)$, e duas delas apresentaram um fenótipo mais específico para a síndrome: fronte proeminente, baixa implantação de cabelo, clinodactilia no $5^{\circ}$ dedo, prega simiesca, frouxidão articular e hipoplasia malar e dentes sobrepostos. A outra paciente apresentou fenótipo normal; menarca aos 12 anos, aos 18 anos engravidou sem intercorrências no período gestacional, e teve um filho normal a termo.

Em sua maioria, as pacientes não têm problemas com infertilidade; na adolescência, porém, algumas apresentam amenorréia, insuficiência ovariana, puberdade tardia e infertilidade (Schinzel, 2001; Linden e Bender, 2002)

A incidência é de 1:1.000 nativivas e, conforme a literatura, as afetadas com triplo $X$ têm aparência normal ao nascimento, sem grandes alterações físicas significativas ao longo do crescimento e desenvolvimento. O retardo mental tende a ser leve, com características mais evidentes para comportamentos imaturos com dificuldade de socialização. Muitos pais descrevem as filhas como muito tímidas e com inclinação à depressão (Linden e Bender, 2002; Linden et al., 2002). 
Essas portadoras podem ter filhos normais, como ocorreu com uma de nossas pacientes, no entanto há um risco aumentado para descendentes com o triplo X ou síndrome de Klinefelter (Kanaka-Gantenbein, et al., 2004).

Segundo Santos et al. (2000), o processo da inativação do cromossomo $\mathrm{X}$ ou a distribuição da linhagem celular no mosaicismo justificariam a aparência normal dessas pacientes. Em contrapartida, há casos em que a portadora pode apresentar malformações congênitas, desde moderadas, como disgenesia ovariana/gonodal, até graves, como agenesia renal (Haverty et al., 2004).

A síndrome de Klinefelter, 47,XXY ocorreu em apenas 1/247 (0,4\%) caso da amostra (Figura 4). O paciente foi diagnosticado, aos seis anos e quatro meses, com fenótipo típico para a síndrome com retardo mental, ginecomastia, características sexuais pouco desenvolvidas e distúrbio de comportamento.

Houve um caso $1 / 267(0,4 \%)$ de síndrome do duplo $Y(47, X Y Y)$ (Figura 4), diagnosticado pelo cariótipo fetal no pré-natal, indicado devido à idade avançada da mãe - 41 anos - e confirmado no cariótipo pós-natal; aos oito meses, o paciente apresentava exame físico e desenvolvimento normal.

Encontramos um caso $(0,4 \%)$ de mosaicismo com três linhagens celulares - 45,X/46,XY/46,Xi(Y) (Figura 5), e o fenótipo incluiu atraso de desenvolvimento neuropsicomotor, dificuldade na linguagem e malformações menores, e também déficit pôndero-estatural, encurtamento de membros 
superiores e genitália masculina normal.

Tivemos um caso $(0,4 \%)$ de triploidia em mosaico - 46,XY/69,XXY $50 \%$ com o número normal de células e 50\% de triploidia (Figura 5), oriundo de uma gestação gemelar monozigótica, com irmão gêmeo e pais sem alteração cromossômica. Ao exame clínico, apresentou um fenótipo característico à literatura, com presença de déficit pôndero-estatural, microcefalia com desproporção crânio-face, sindactilia, hipospádia, assimetria bilateral de membros, e está vivo, atualmente com 10 anos de idade.

Três linhagens celulares

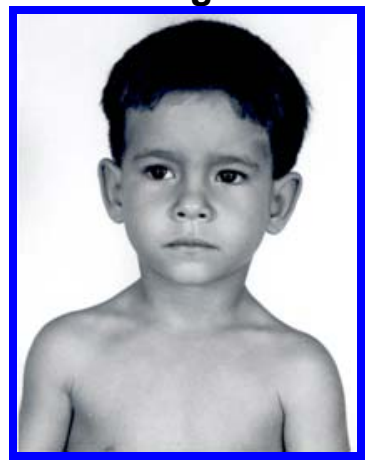

cariótipo 45,X/46,XY/46,Xi(Y) 5 anos e 4 meses

\section{Diploidia/Triploidia}

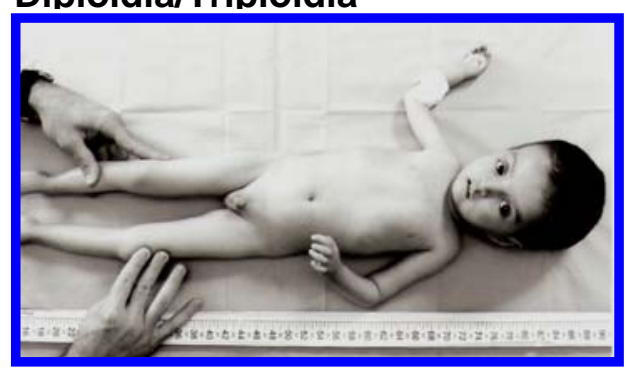

cariótipo 46,XY/69,XXY 1 ano e 10 meses

Figura 5: Foto do paciente portador de três linhagens celulares e do portador de diploidia/triploidia.

As poliploidias são consideradas letais, exceto nos casos de mosaicismo, e podem apresentar sobrevida prolongada, pela distribuição das linhagens em graus variados de células diplóides normais e triplóides, o que resulta em malformações mais brandas no portador (Graham et al., 1981). 
A triploidia em mosaico, em $75 \%$ dos casos, é revelada quando são analisados os fibroblastos. van de Laar et al. (2002) relataram três casos com retardo mental combinado com o retardo no crescimento, obesidade troncal, assimetria bilateral, hipotonia, sindactilia, clino-camptodactilia e orelhas de baixa implantação. Os resultados obtidos da análise de sangue periférico de todos os 3 pacientes foram inicialmente normais; porém, posteriormente a triploidia em mosaico foi revelada em todos eles, pela pesquisa com fibroblastos.

\subsubsection{AberRações Cromossômicas Estruturais}

A pesquisa de alterações estruturais é muito importante, tanto no prognóstico de pacientes, quanto em casais com história de abortos recorrentes ou de infertilidade.

Conforme Van Dyke et al. (1983), a freqüência aproximada dessas alterações é $0,32 \%$ nos nascidos vivos; no entanto, esse número poderia ser mais elevado, se os casos de abortos fossem devidamente analisados.

As aberrações estruturais foram identificadas em 72/247 (29\%), e as deleções, translocações e duplicações foram as mais encontradas. As principais aberrações cromossômicas estruturais encontradas estão representadas na Tabela 4. 
Tabela 4: Aberrações cromossômicas estruturais identificadas nos pacientes

\begin{tabular}{|c|c|c|c|c|}
\hline Alteração cromossômica & Cariótipo & $\begin{array}{l}\mathrm{n}^{\circ} \mathrm{de} \\
\text { casos }\end{array}$ & Total & $\%{ }^{* *}$ \\
\hline \multirow[t]{10}{*}{ Deleção } & $46, X X$, del $(4 p)$ ou $47, X Y$, del $(4 p)$ & 8 & \multirow{10}{*}{27} & \multirow{10}{*}{10,8} \\
\hline & $46, X X, \operatorname{del}(5 p)$ ou $47, X Y, \operatorname{del}(5 p)$ & 9 & & \\
\hline & $46, X X, \operatorname{del}(6 q)$ & 1 & & \\
\hline & $46, X X, \operatorname{del}(7 p)$ & 1 & & \\
\hline & $46, X Y, \operatorname{del}(11 q)$ & 1 & & \\
\hline & $46, X X, \operatorname{del}(13 q)$ & 3 & & \\
\hline & $46, X Y, \operatorname{del}(14 q) / 46, X Y$ & 1 & & \\
\hline & $46, X X, \operatorname{del}(18 q)$ & 1 & & \\
\hline & $46, X X, \operatorname{del}(22 q)$ & 1 & & \\
\hline & $46, X Y, \operatorname{del}(X q)$ & 1 & & \\
\hline \multirow[t]{12}{*}{ Duplicação } & $46, X X, \operatorname{dup}(3 q)$ & 1 & \multirow{12}{*}{14} & \multirow{12}{*}{5,6} \\
\hline & $46, X Y, \operatorname{dup}(3 p)$ & 1 & & \\
\hline & $46, X Y, \operatorname{dup}(4 p)$ & 1 & & \\
\hline & $46, X X, \operatorname{dup}(4 q)$ & 1 & & \\
\hline & $46, X Y, \operatorname{dup}(9 p)$ & 1 & & \\
\hline & $46, X X, \operatorname{dup}(9 q)$ & 2 & & \\
\hline & $46, X Y, \operatorname{dup}(13 q)$ & 1 & & \\
\hline & $46, X Y, \operatorname{dup}(14 p)$ & 1 & & \\
\hline & $46, X Y, \operatorname{dup}(15 p)$ & 1 & & \\
\hline & $46, X X, \operatorname{dup}(16 q)$ ou $46, X Y, \operatorname{dup}(16 q)$ & 2 & & \\
\hline & $46, X Y, \operatorname{dup}(18 p)$ & 1 & & \\
\hline & $46, X Y, \operatorname{dup}(22 q)$ & 1 & & \\
\hline \multirow[t]{2}{*}{ Inversão } & $46, X X, \operatorname{inv}(9)$ ou $46, X Y, \operatorname{inv}(9)$ & 5 & & \\
\hline & $46, X Y, \operatorname{inv}(Y)$ & 1 & 6 & 2,4 \\
\hline \multirow[t]{7}{*}{ Anel } & $46, X X, r(2)$ & 1 & \multirow{7}{*}{9} & \multirow{7}{*}{3,6} \\
\hline & $46, X X, r(4)$ & 1 & & \\
\hline & $46, X X, r(10)$ & 1 & & \\
\hline & $46, X X, r(18)$ & 1 & & \\
\hline & $46, X X, r(22)$ & 2 & & \\
\hline & $46, X X / 47, X X+r$ & 1 & & \\
\hline & $46, X Y / 47, X Y+r$ & 2 & & \\
\hline \multirow[t]{6}{*}{ Translocação } & $46, X X,+t(7 p ; 14 q)$ & 1 & \multirow{6}{*}{6} & \multirow{6}{*}{2,4} \\
\hline & $46, X X,+t(11 q ; 13 q)$ & 1 & & \\
\hline & $46, X X,+t(16 q ; 18 p)$ & 1 & & \\
\hline & $46, X X,+t(X p ; 8 p)$ & 1 & & \\
\hline & $46, X X, \operatorname{der}(7)(7 ; 8)$ & 1 & & \\
\hline & $46, X Y, \operatorname{der}(15)(14 ; 15)$ & 1 & & \\
\hline \multirow[t]{4}{*}{ Adição } & $46, X X, \operatorname{add}(4 p)$ & 1 & \multirow{4}{*}{4} & \multirow{4}{*}{1,6} \\
\hline & $46, X X, \operatorname{add}(6 p)$ & 1 & & \\
\hline & $46, X X, \operatorname{add}(9 p)$ & 1 & & \\
\hline & $46, X Y, \operatorname{add}(10 q)$ & 1 & & \\
\hline \multirow[t]{3}{*}{ Marcador } & $46, X X,+\operatorname{mar}$ & 1 & \multirow{3}{*}{4} & \multirow{3}{*}{1,6} \\
\hline & $47, X Y,+$ mar & 2 & & \\
\hline & $46, \mathrm{XY} / 47, \mathrm{XY},+$ mar & 1 & & \\
\hline \multirow{2}{*}{ Isocromossomo } & $46, X X, i(18 q)$ & 1 & & \\
\hline & $46, X X, i 18$ & 1 & 2 & 0,8 \\
\hline Total Geral & & 72 & & 29,2 \\
\hline
\end{tabular}




\section{- Deleções}

No presente trabalho, o evento mais freqüente das aberrações estruturais foi a deleção, $27 / 247(10,9 \%)$ casos. Dentre elas, foram diagnosticados com maior ocorrência a síndrome de "Cri-du-chat" (5p-) (9 pacientes) e a síndrome de Wolf - Hirschhorn (4p-) (8 pacientes) (Figura 6). Os pais desses portadores apresentaram uma análise cromossômica normal, tratando-se de eventos esporádicos, portanto o risco de recorrência é muito baixo.

Síndrome de "Cri-du-chat"

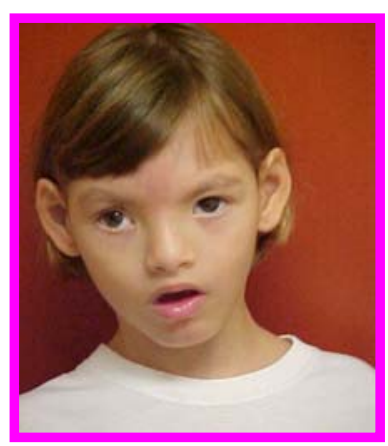

cariótipo $46, X X, 5 p-$ 7 anos

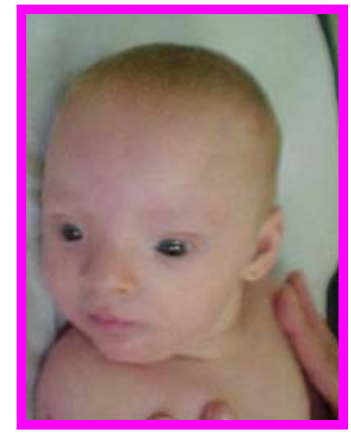

cariótipo $46, X X, 5 p-$ 7 meses

Síndrome de Wolf-Hirchhorn

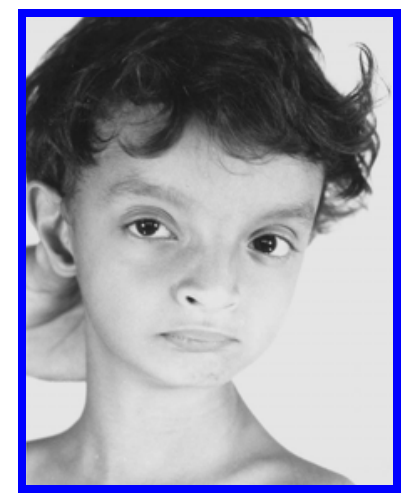

cariótipo $46, X Y, 4 p$ -

8 anos e 8 meses

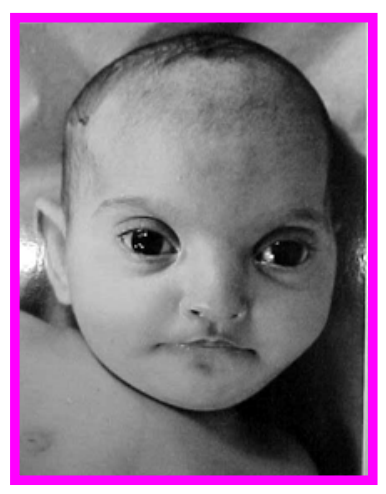

cariótipo $46, X X, 4 p-$

2 anos e 5 meses

Figura 6: Fotos de portadores das síndrome de "Cri-du-chat" e de WolfHirchhorn 
Em geral as deleções são encontradas no diagnóstico de pacientes dismórficos e no pré-natal, mas o conhecimento do funcionamento do gene deletado e sua relação com a caracterização fenotípica ainda não são muito bem definidos. Deleção resulta numa haploinsuficiência, que parece depender do tamanho do segmento deletado, assim como do número e da função dos genes ali envolvidos (Shaffer e Lupski, 2000; Zollino et al.,2000).

Na deleção do $5 p$, também conhecida como síndrome de "Cri-duchat", os pacientes do presente trabalho apresentaram características semelhantes às apontadas na literatura: baixo peso ao nascimento, choro característico (como o miado de um gato), hipotonia, microcefalia, hipertelorismo, epicanto, estrabismo, ponte nasal baixa, retro e micrognatia, crescimento lento e retardamento mental (Cerruti Minardi et al, 2002).

Na deleção do $4 p$, síndrome de Wolf-Hirschhorn, as características encontradas também foram semelhantes às apontadas na literatura. Os pacientes apresentaram deficiência mental, alterações crânio-faciais (incluindo microcefalia, fronte ampla e alongada típica - glabela), microftalmia e hipertelorismo, retardo do crescimento pré e pós-natal, hipotonia e convulsão (Hirschhorn e Cooper, 1961; Zollino et al., 2000).

\section{- $\underline{\text { Translocação }}$}

Translocações ocorreram em 6/247 (2,4\%) pacientes, e todos esses casos foram herdados de um dos genitores, que apresentou, em seus cariótipos, translocações equilibradas. 
A translocações equilibradas são as mais encontradas no homem $(0,5 \%)$ (Jacobs, 1992b), e podem passar despercebidas por muitas gerações, já que os portadores normalmente não produzem fenótipo, até surgirem problemas reprodutivos ou prole com malformação.

Os pacientes com os cariótipos $46, \mathrm{XX}, \operatorname{der}(7)(7 ; 8), \quad 46, \mathrm{XY}$, $\operatorname{der}(15)(14 ; 15)$ e $46, X X,+t(16 q ; 18 p)$ apresentaram o mesmo tipo de translocação equilibrada do genitor portador, e o estudo cromossômico familial identificou outros parentes portadores da mesma translocação, os quais também eram normais (avós e tios). Contudo, nossos pacientes apresentaram atraso no desenvolvimento neuropsicomotor e dismorfismos fenotípicos.

Na literatura há casos de famílias que, embora com o mesmo tipo de translocação, apresentam portadores com ou sem fenótipo. Esses casos são de interesse para o estudo genético, embora ainda permaneçam não esclarecidos. Aparentemente, sugere-se que ocorram quebras nos pontos translocados, rupturas de genes ou mesmo pequenas duplicações que não podem ser vistas ao microscópio. Quanto menor for o tamanho do material em excesso ou perdido, maior a incidência em nativivos, sendo indicado, nesses casos, o estudo molecular (Flint, et al., 1995; Schinzel, 2001; Gribble et al., 2005).

Portanto, os genitores com translocações equilibradas apresentam um risco aumentado de transmissão aos filhos, que terão rearranjos cromossômicos em desequilíbrio, com perda ou ganho de material genético, 
o que resulta em fenótipos anormais com graus variados de retardo mental (Jacobs, 1992a; Cohen et al., 1995; Celep et al., 2006a).

\section{- Duplicação}

As duplicações ocorreram em 14/247(5,6\%) casos, em diferentes cromossomos (Tabela 4). Nos pacientes que apresentam os cariótipos 46,XX,dup(3q), 46,XX,dup(4q) e 46,XY,dup(18p), foi confirmada herança parental de rearranjo equilibrado. E, no caso da duplicação do 18p, após estudo dos cromossomos da família foi também observada a mesma duplicação no tio paterno, que apresentava retardo mental leve.

Essa alteração acarreta a presença de trissomias parciais do segmento duplicado, resultando em manifestações fenotípicas variadas, dependendo do cromossomo e do tamanho do material duplicado (Schinzel, 2001).

A presença de duplicações pode ter como causa erros na meiose ou na mitose, ou, ainda, pode ser decorrente da segregação dos cromossomos translocados recebidos dos genitores portadores de uma translocação cromossômica equilibrada durante a meiose (Cohen et al., 1995, Schinzel, 2001).

- Anel

O cromossomo em anel é uma ocorrência rara, e seu grau da expressão fenotípica depende do tamanho da deleção e do quanto de 
material genético foi perdido no seu processo de formação. Assim, o quadro clínico de pacientes com cromossomo em anel pode variar; no entanto, são normalmente avaliados em citogenética, por apresentarem retardo mental e dismorfismos.

Segundo Cotè et al. (1981), a síndrome do anel tem como características: baixo peso ao nascimento, retardo de crescimento grave, retardo mental de leve a moderado, sem desvios fenotípicos, independentemente do cromossomo considerado. Entretanto, quanto maior for o cromossomo envolvido, maior o retardo de crescimento (Kosztolányi, 1987).

Em nossa casuística, o anel foi encontrado em $9 / 247(3,6, \%)$ casos, e em nenhum deles foi uma característica herdada, sendo, portanto, casos de novo. As alterações clínicas encontradas foram: déficit ponderal e estatural (8/9), atraso/retardo mental (7/8), distúrbio de fala (7/9), alterações do sistema nervoso central (2/9), dismorfismos craniofaciais (6/9), displasia auricular (5/9), microcefalia (3/9), alterações esqueléticas (3/9), estrabismo e alterações geniturinárias (3/12).

Nossos achados mostraram concordância com a literatura. A presença da cútis girata, em um de nossos casos de anel do 22 (Figura 7a) já descrita anteriormente por Anderlid et al. (2002), demonstra que esse achado talvez faça parte do conjunto de alterações específicas do cromossomo 22. Por outro lado, a displasia auricular, comum em diversas aberrações cromossômicas, em nossa casuística também foi significativa (7/9). 


\section{Cromossomo em anel}

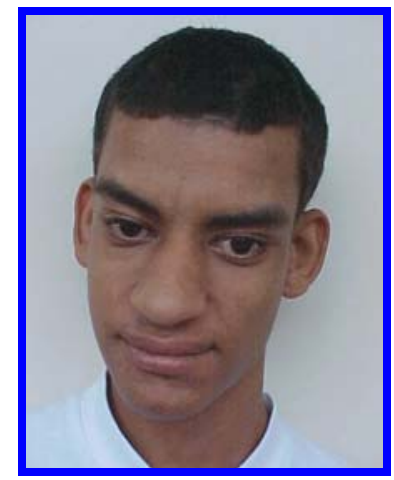

a) cariótipo $46, X Y, r(22)$

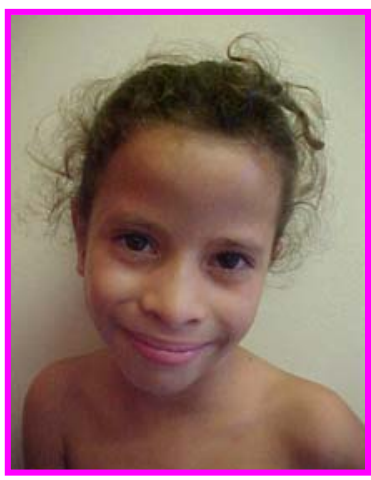

b) cariótipo $46, X X, r(5)$

Figura 7: Fotos de pacientes portadores de cromossomo em anel

As deleções subteloméricas do 22q (Flint et al., 1995) constituem causas de retardo mental e de características fenotípicas dismórficas menos expressivas, porém a deficiência na fala é significativa e mais intensificada nos casos de cromossomos em anel do 22, exatamente como descrito no nosso caso. Porém, nosso caso apresenta déficit pôndero-estatural, o que é explicado pela formação do anel. Essa situação também foi relatada por Luciani et al. (2003), que estudaram pacientes com deleção telomérica do 22q13 resultante de anel e não encontraram diferença no fenótipo entre a del(22q13) e o anel do 22. Contudo, os que apresentavam apenas a del(22q13) tinham um crescimento acelerado, enquanto os pacientes com $\mathrm{r}(22)$ apresentavam déficit de crescimento global.

- Inversão

Neste trabalho, foram detectados $6 / 247(2,4 \%)$ casos de inversão; cinco envolveram a região pericêntrica do cromossomo 9 , e um, o 
cromossomo Y. Entre os cinco probandos com inversão do cromossomo 9 , quatro foram herdados dos pais, que apresentavam fenótipo normal (um materno e três paternos), enquanto em um caso os pais estão em estudo.

As inversões pericêntricas normalmente não têm conseqüências fenotípicas, sendo consideradas polimorfismos, transmitidos de geração em geração, embora em alguns casos apareçam associadas à infertilidade, abortos consecutivos e anomalias congênitas (Krishna et al, 1992).

Curiosamente, os pacientes com inversão, aqui relacionados, apresentavam atraso no desenvolvimento psicomotor, retardo mental e dismorfismos, como microcefalia (2/6), fácies peculiar (5/6), fendas palpebrais inclinadas para cima $(3 / 6)$, ponte nasal baixa $(2 / 6)$, microretrognatia (1/6), pescoço alado (1/6), prega palmar única (2/6) e camptodactilia (1/6). Em três casos de inversão do 9, foi observado o déficit pôndero-estatural, e dois manifestaram convulsão desde um ano de idade.

$\mathrm{Na}$ literatura, a presença do retardo mental e de crescimento foi observada em alguns casos de inversão do cromossomo 9, embora isso leve a discussões significativas sobre uma possível correlação genótipo-fenótipo (Kanata et al., 1985; Samonte et al., 1996).

\section{- Marcador e outros}

As alterações cromossômicas estruturais menos freqüentes foram: marcador (4/247), assim chamados por serem cromossomos muito pequenos e ocasionalmente vistos em cariótipos; adição (4/247), que ocorre 
quando o braço cromossômico está aumentado, devido à aquisição de material cromossômico a mais; e o isocromossomo (2/247), que resulta em um cromossomo com um dos "braços" ausente e o outro duplicado.

Todas essas alterações são de difícil caracterização, sendo necessárias, portanto, outras técnicas, para estudos mais específicos, tais como: a hibridação por fluorescência in situ (FISH), que utiliza sondas de DNA; a SKY- cariótipo espectral, que possibilita a visualização de cada um dos pares de cromossomos e os cromossomos sexuais $\mathrm{X}$ e $\mathrm{Y}$ em cores diferentes; array-CGH, que é baseado na hibridização genômica comparativa; e, a multiplex Ligation-dependent Probe Amplification (MLPA). Todas essas técnicas possibilitam identificar regiões de anormalidades cromossômicas estruturais submicroscópicas, microdeleções e microduplicações (Trask, 2002; Sharkey et al., 2005).

\section{Consideracões Finais:}

A alta freqüência de aberrações cromossômicas encontrada no presente trabalho enfatiza a importância do exame citogenético (cariótipo) na investigação diagnóstica de rotina nos pacientes atendidos na Unidade de Genética do ICr, para definição diagnóstica e aconselhamento genético adequado aos pacientes e seus familiares.

Por outro lado, os pacientes que apresentaram o resultado de cariótipo normal não podem ser afastados, visto que possíveis alterações 
submicroscópicas não foram diagnosticadas pela citogenética convencional técnica da banda G. Vários estudos demonstraram que 3-7\% de pacientes com retardo mental inespecífico, associado ou não ao atraso no desenvolvimento e dismorfismos, apresentam alterações submicroscópicas. Necessita-se, portanto, de técnicas complementares mais modernas, na elucidação desses casos, como o FISH, array - CGH, SKY e MLPA (Flint, et al., 1995, Knight et al.,1999, Kirtchhoff et al., 2007). No Brasil, na Universidade de São Paulo, uma pesquisa foi desenvolvida recentemente por Krepischi et al., 2006, que utilizaram o CGH em 95 pacientes com fenótipo alterado, mas com resultado de banda G normal, e demonstraram alterações cromossômicas em $30 \%$ dos casos.

Embora essas técnicas sejam extremamente eficientes, os custos elevados dificultam sua realização em grande parte dos laboratórios de citogenética do Brasil. Desse modo, em nosso meio, o estudo cromossômico pela banda $G$ é o primeiro exame indicado após a avaliação clínica do paciente.

Os testes moleculares mais específicos são indicados nos casos dos pacientes com resultado normal pelo cariótipo, porém com fenótipo sugestivo para aberração cromossômica, o que possibilita prosseguimento na investigação diagnóstica. 
5. ConClusões

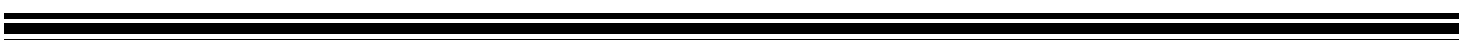


- O estudo cromossômico pela banda G permitiu-nos identificar uma freqüência de aberrações cromossômicas em $22 \%$ dos pacientes atendidos na unidade de Genética do ICr.

- As aberrações cromossômicas numéricas foram mais freqüentes, pois foram encontradas em $70,8 \%$. As estruturais foram encontradas em $29,2 \%$.

- As aberrações envolvendo os cromossomos autossomos ocorreram em maior freqüência (89,5\%), em relação às aberrações sexuais $(10,5 \%)$.

- Das anormalidades autossômicas, a síndrome de Down foi a mais freqüente, com 47,4\%, seguida da S. Edwards, com 7,3\%, e da S. Patau, com $3,6 \%$.

- Dentre as alterações nos cromossomos sexuais, a síndrome de Turner apareceu com maior freqüência, com 7,3\%.

- Entre as alterações estruturais, a que apresentou maior freqüência foi a deleção, com 10,9\%, com maior incidência para o 5p-, síndrome "Cridu-chat" (9 pacientes) e o 4p-, síndrome Wolf-hirshhorn (8 pacientes).

- A alta freqüência obtida na casuística enfatiza a importância do estudo cromossômico nos pacientes com retardo mental, dismorfismos e múltiplas malformações congênitas, a fim de oferecer um aconselhamento genético adequado ao paciente e seus familiares.

- Nos casos de cariótipo normal em pacientes com quadro clínico sugestivo de presença de aberração cromossômica, a investigação diagnóstica deverá prosseguir com outras técnicas específicas. 
6. Referências 
Albano LM. Importância da genética no serviço público: relato da extinção de um setor de genética no município de São Paulo, Brasil. Rev Panam Salud Publica. 2000;7:29-34.

Anderlid BM, Schoumans J, Annerén G, Sahlén S, Kyllerman M, Vujic M, Hagberg B, Blennow E, Nordenskjöld M. Subtelomeric rearrangements detected in patients with idiopathic mental retardation. Am J Med Genet. 2002;107:275-84.

Balarin MAS, Lopes VLGS, Silva RL, Araújo JS. Quatro anos do ambulatório de aconselhamento genético na Faculdade de Medicina do Triângulo Mineiro: estudo retrospectivo. Rev Med Minas Gerais. 1995;5:214-8.

Bugge M, Collins A, Petersen MB, Fisher J, Brandt C, Hertz JM, Tranebjaerg L, de Lozier-Blanchet C, Nicolaides P, Brondum-Nielsen K, Morton N, Mikkelsen M. Non-disjunction of chromosome 18. Hum Mol Gen. 1995;4:2227-32.

Cans C, Cohen O, Lavergne C, Mermet MA, Demongeot J, Jalbert P. Human reciprocal translocations: is the umbalanced mode at birth predictable? Hum Genet. 1993;91:228-232.

Carakushansky G, Teich E, Ribeiro MG, Horowitz DD, Pellegrini S. Diploid/triploid mosaicism: further delineation of the phenotype. Am J Med Genet. 1994;52:399-401.

Casperson T, Zech L, Johansson C. Differential banding of alkylating fluorochromes in human chromosomes. Exp. Cell Res. 1970;60:315-19.

Celep F, Karagüzel A, Ozeren M, Bozkaya $\mathrm{H}$. Chromosomal abnormalities in 457 Turkish patients with MCA/MR. Turk J Pediatr. 2006a;48:130-4.

Celep $F$, Karagüzel $A$, Ozeren $M$, Bozkaya $H$. The frequency of chromosomal abnormalities in patients with reproductive failure. Eur $\mathrm{J}$ Obstet Gynecol. 2006b;106-9.

Cerruti Minardi P, Perfumo C, Cali A, Coucourde G, Pastore G, Cavani S, Zara F, Overhauser J, Pierluigi M, Dagna BF. Clinical and molecular characterization of 80 patients with $5 p$ deletion: genotype-phenotype correlation. J Med Genet. 2002;38:151-8.

Cohen O, Cans C, Mermet MA, Demongeot J J, Jalbert P. Viability threshold for partial trisomies and monosomies. A study of 1,159 viable unbalanced reciprocal translocations. Hum Genet. 1995;93:188-94.

Cotè GB, Katsantoni A, Deligeorgis D. The cytogenetic and clinical implications of a ring chromosome 2. Ann Genet. 1981;24:231-5. 
Daniel A, Wu Z, Darmanian A, Collins F, Jackson J. Three different origins for aparent triploid/diploid mosaics. Prenatal Diagn. 2003;23:529-34.

Dewald G, Alvarez MN, Clouthier MD, Kelalis PP, Gordon H. A diploidtriploid human mosaic with cytogenetic evidence of double fertilization. Clin Genet. 1975;8:149-60.

de Vries BB, White SM, Knight SJ, ReganR, Homfray T, Young ID, Super M, McKeown C, Splitt M, Quarrel OW, Trainer AH, Niermeijer MF, Malcolm S, Flint J, Hurst JA, Winter RM. Clinical studies on subtelomeric rearrangements: a checklist. J Med Genet. 2001;38:140-50.

Duarte AC, Cunha E, Roth JM, Ferreira FLS, Garcias GL, Martino-Roth MG. Cytogenetics of genetic counseling patients in Pelotas, Rio Grande do Sul, Brazil. Genet Mol Res. 2004;3:303-8.

Edelmann L, Pandita RK, Morrow BE. Low-copy repeats mediate the comom $3 \mathrm{Mb}$ deletions in patients with velocardio-facial syndrome. $\mathrm{Am} \mathrm{J}$ Hum Genet. 1999;64:1076-86.

El-Shanti $\mathrm{H}$, Al-Alami J. The pattern of peripheral blood chromosomal abnormalities in Northern Jordan. Saudi Med J. 2002;23:1552-4.

Flint J, Wilkie AO, Buckle VJ, Winter RM, Holland AJ, McDermid HE. The detection of subtelomeric chromosomal rearrangements in idiopathic mental retardation. Nat Genet. 1995;9:132-40.

Fryns JP, Buggenhout GV. Structural chromosome rearrangements in couples with recurrent fetal wastage. Eur J Obstet Gynecol Reprod Biol. 1998;81:171-6.

Gardner RJM, Sutherland GR. Cromosome abnormalities and genetic counselling. New York:Oxford University Press;1996.

Giaccardi A, Sardi R, Priora U, Vivalda M, Domeneghetti G, Giro P. Trissomia 18 o sindrome di Edwards. Minerva Pediatr. 1991;43:343-9.

Goud MT, Al-Harassi SM, Al-Khalili SA, Al-Salmani KK, Al-Busaidy SM, Rajab A. Incidence of chromosome abnormalities in the Sultanate of Oman. Saudi Med J. 2005;26:1951-7.

Graham JM, Hoehn H, Lin MS, Smith DW. Diploid-triploid mixoploidy: clinical and cytogenetic aspects. Pediatrics. 1981;68:23-8.

Gribble SM, Prigmore E, Burford DC, Porter KM, Ng BL, Douglas EJ, Fiegler $\mathrm{H}$, Carr P, Kalaitzopoulos D, Clegg S, Sandstrom R, Temple IK, Youings SA, Thomas NS, Dennis NR, Jacobs PA, Crolla JA, Carter NP. The complex nature of constitutional de novo apparently balanced translocations in patients presenting with abnormal phenotypes. J Med Genet. 2005;42:8-16. 
Hall H, Hunt P, Hassold T. Meiosis and sex chromosome aneuploidy: how meiotic errors cause aneuploidy; how aneuploidy causes meiotic errors. Curr Opin Genet Dev. 2006; 16:323-9.

Hamerton JL, Cannig N, Ray M, Smith S. A cytogenetic survey of 14,069 newborn infants. I. Incidence of chromosome abnormalities. Clin Genet. 1975;8:223-43.

Hassold TJ. Nondisjunction in the human male. Curr Top Dev Biol. 1998;37:383-406.

Hassold T, Abruzzo M, Adkins K, Griffin D, Merrill M Millie E, Saker D, Shen J, Zaragoza M. Human aneuploidy: incidence, origin, and etiology. Environ Mol Mutagen. 1996;28:167-75.

Hassold T, Chiu D. Maternal age-specific rates of numerical chromosome abnormalities with special reference to trissomy. Human Genet. 1985;70:11-7.

Hassold T, Hunt P. To err (meiotically) is human: the genesis of human aneuploidy. Nat Rev Genet. 2001;2:280-91.

Hassold TJ, Jacobs PA. Trisomy in man. Annu Rev Genet. 1984;18:69-97.

Hassold T, Sherman S, Hunt P. Counting crossovers: characterizing meiotic recombination in mammals. Hum Mol Genet. 2000;9:2409-19.

Haverty CE, Lin AE, Simpson E, Spencer MA, Martin RA. 47,XXX associated with malformations. Am J Med Genet A. 2004;125:108-11.

Henderson SA, Edwards RG. Chiasma frequency and maternal age in mammals. Nature.1968;218:22-8.

Hirshhorn K, Cooper HL, Firschein IL. Apparent deletion of short arms of one chromosome (4-5) in a child with defects of midline fusion. Hum Chromosome Newsl. 1961;4:14.

Horovitz DDG, Llerena Jr JC, Mattos RA. Atenção aos defeitos congênitos no Brasil: Panorama atual. Cad Saúde Publica. 2005;21:1055-64.

Jacobs PA. The chromosome complement of human gametes. Oxf Rev Reprod Biol. 1992a;14:47-72.

Jacobs PA, Browne C, Gregson N. Estimates of the frequency of chromosome abnormalities detectable in unselected newborns using moderate levels of banding. J Med Genet. 1992b;29:103-8. 
Jacobs $\mathrm{P}$, Dalton $\mathrm{P}$, James R, Mosse K, Power M, Robinson D, Skuse D. Turner syndrome: a cytogenetic and molecular study. Ann. Hum. Genet. 1997;61:471-83.

James RS, Dalton P, Gustashaw K, Wolff DJ, Willard HF, Mitchell C, Jacobs PA. Molecular characterization of isochromosomes of Xq. Ann Hum Genet. 1997;61:485-90.

Jones KLS. Recognizable patterns of human malformation. $6^{\mathrm{a}} \mathrm{Ed}$. Philadelphia: Elsevier Saunders; 2006.

Kanata S, Kadotani T, Watanabe Y, Matsuo N, Kodama H, Kubo S. A case of mental retardation having pericentric inversion on $\mathrm{n}^{\circ} 9$ chromosome. Pro Jpn Acad. 1985;61:242-4.

Kanaka-Gantenbein C, Kitsiou S, Mavrou A, Stamoyannou L, Kolialexi A, Kekou K, Liakopoulou M, Chrousos G. Tall stature, insulin resistance, and disturbed behavior in a girl with the triple $X$ syndrome harboring three SHOX genes: offspring of a father with mosaic Klinefelter syndrome but with two maternal X chromosomes. Horm Res. 2004;61(5):205-10.

Kirchhoff M, Bisgaard AM, Bryndorf T, Gerdes T. MLPA analysis for a panel of syndromes with mental retardation reveals imbalances in $5.8 \%$ of patients with mental retardation and dysmorphic features, including duplications of the Sotos syndrome and Williams-Beuren syndrome regions. Eur J Med Genet. 2007;50:33-42.

Kline J, Kinney A, Levin B, Warburton D. Trisomic pregnancy and earlier age at menopause. Am J Hum Genet. 2000;67:395-404.

Knight SJ, Regan R, Nicod A, Horsley SW, Kearney L, Homfray T, Winter $\mathrm{RM}$, Bolton $\mathrm{P}$, Flint J. Subtle chromosomal rearrangements in children with unexplained mental retardation. Lancet. 1999; 13: 1676-81.

Krepischi-Santos AC, Vianna-Morgante AM, Jehee FS, Passos Bueno MR, Knijnenburg J, Szuhai K, Sloos W, Mazzeu JF, Kok F, Cheroki C, Otto PA, Mingroni-Netto RC, Varela M, Koiffmann C, Kim CA, Bertola DR, Pearson $\mathrm{PL}$, Rosenberg $\mathrm{C}$. Whole-genome array-CGH screening in undiagnosed syndromic patients: old syndromes revisited and new alterations. Cytogenet Genome Res. 2006;115(3-4):254-61

Kosztolányi G : Does "ring syndrome"exist? An analysis of 207 case reports on patients with a ring autosome. Hum Genet. 1987;75:174-9.

Krishna DS, Al-Awadi SA, Farag TI. Pericentric inversion and recombinant aneusomy and other associated chromosomal aberrations: random or nonrandom. Am J Hum Genet. 1992;51:A291(1146).

Lamb NE, Freeman SB, Savage-Austin A, Pettay D, Taft L, Hersey J,Gu Y, Shen J, Saker D, May KM, Avramopoulos D, Petersen MB, Hallberg A, 
Mikkelsen M, Hassold TD, Sherman SL. Susceptible chiasmate configurations of chromosome 21 predispose to non-disjunction in both maternal meiosis I and meiosis II. Nat Genet.1996;14:400-5.

Lamb, NE, Gu Y, Shaffer J, Feigold E, Sherman SL. Association between maternal age and meiotic recombination for trisomy 21. Am J Hum Genet. 2005;76:91-9.

Larsen $\mathrm{T}$, Gravholt $\mathrm{CH}$, Tillebeck A, Larsen $\mathrm{H}$, Jensen MB, Nielsen $\mathrm{J}$, Friedrich $U$. Parental origin of the $X$ chromosome, $X$ chromosome mosaicism and screening for"hidden" $Y$ chromosome in 45,X Turner syndrome ascertained cytogenetically. Clin Genet. 1995;48:6-11.

Linden MG, Bender BG. Fifty-one prenatally diagnosed children and adolescents with sex chromosome abnormalities. Am J Med Genet. 2002;110:11-8.

Linden MG, Bender BG, Robinson A. Genetic counseling for sex chromosome abnormalities. Am J Med Genet. 2002;110:3-10.

Lippe B. Turner syndrome. Endocrinol Metab Clin North Am. 1991;20:121-52.

Luciani JJ, Mas de P, Depetris D, Mignon-Ravix C, Bottani A, Prieur $M$, Jonveaux P, Philippe A, Bourrouillou G, Martinvile B de, Delobel B, Vallee L, Croquette M-F, Mattei M-G. Telomeric 22q13 deletions resulting from rings, simple deletions, and translocations: cytogenetic, molecular, and clinical analyses of 32 new observations. J Med Genet. 2003;40:690-96.

McDermott A, Voyce MA, Romain D. Ring chromosome 4. J Med Genet. 1977;14:228-32.

McFadden DE, Langlois S. Parental and meiotic origin of triploidy in the embryonic and fetal periods. Clin Genet. 2000;58:192-200.

Mokhtar MM. Chromosomal aberrations in children with suspected genetic disorders. East Med Health J. 1997;1:114-22.

Moorhead PS, Nowell PC, Mellnan WJ, Battips DM, Hunguford DA. Chromosome preparations of leukocytes cultured from human peripheral blood. Exp Cell Res. 1960;20:613-6.

Morton NE, Jacobs PA, Hassold T, Wu D. Maternal age in trisomy. Ann Hum Genet. 1988;52:227-35.

Muller U, Weber JL, Berry P, Kupke KG. Second polar body incorporation into a blastomere results in 46,XX/ 69,XXX mixoploidy. J Med Genet. 1993;30:597-600.

Mutton D, Alberman E, Hook EB. Cytogenetic and epidemiological findings in Down syndrome, England and Wales 1989 to 1993. National Down 
Syndrome Cytogenetic Register and the Association of Clinical Cytogeneticists. J Med Genet. 1996;33:387-94

Nazer J, Antolini M, Juarez ME, Cifuentes L, Hubner ME, Pardo A, Castillo S. Prevalence of chromosomal aberrations at birth in the Clinical Hospital of Universidad de Chile. Rev Med Chile. 2001;131:651-8.

Nussbaum M, Mclnnes R, Willard R. Thompson \& Thompson. Genetics in Medicine. $6^{\text {th }}$ ed. Philadelphia:Saunders; 2004.

Organização Pan-Americana da Saúde (OPS). Prevenção e controle de enfermidades genéticas e os defeitos congênitos: relatório de um grupo de consulta. (publicação científica, n.460). Washington DC:USA;1984.

Redheendran R, Neu RL, Bannerman RM. Long survival in trisomy-13syndrome: 21 cases including prolonged survival in two patients 11 and 19 years old. Am J Med Gen. 1981;8:167-72.

Samonte RV, Conte RA, Ramesh KH, Verma RS. Molecular cytogenetic characterization of breakpoints involving pericentric inversions of human chromossome 9. Human Genet. 1996;98:576-80.

Santos CB, Boy RT, Santos JM, Silva MPS, Pimentel MMG. Chromosomal investigations in patients with mental retardation and/or congenital malformations. Mental retardation. Genet Mol Biol. 2000;23:703-7.

Schinzel A. Catalogue of unbalanced chromosome aberrations in man. 2th ed. NY: Walter de Gruyter;2001.

Seabright M. A rapid banding technique for human chromosome. Lancet. 1971;2:971-2.

Serviço de Aconselhamento Genético do Departamento de Biologia da Universidade Federal do Espírito Santo (SAG-EFES);1998. Disponível em <http://www.ufes.br/ dbios/sag.htm> Acesso em 5 jul 2006.

Shaffer LG, Lupski JR. Molecular mechanisms for constitutional chromosomal rearrangements in humans. Annu Rev Genet. 2000;34:297329.

Sharkey FH, Maher E, FitzPatrick DR. Chromosome analysis: what and when to request. Arch Dis Child. 2005;90:1264-9.

Sugayama SMM, Kim CA, Leone CR, Diniz EMA, Koiffmann CP, Gonzalez $\mathrm{CH}$. História natural de 24 pacientes com trissomia 18 (syndrome de Edwards) e de 20 pacientes com trissomia 13 (síndrome de Patau). Pediatria(São Paulo). 1999;21:69-77.

Swansbury J. Some difficult choices in cytogenetics. Methods Mol Biol. 2003;220:245-57. 
Therman E, Susman B, Denniston C. The nonrandom participation of human acrocêntric chromosomes in Robertsonian translocations. Ann Hum Genet. 1989;3:97:26-34.

Thomas NS, Ennis S, Sharp AJ, Durkie M, Hassold TJ, Collins AR, Jacobs $P A$. Maternal sex chromosome non-disjunction: evidence for $X$ chromosome-specific risk factors. Hum Mol Genet. 2001;10:243-50.

Trask, BJ. Human Cytogenetics: 46 chromosomes, 46 years and counting. Nature R Genet. 2002;3:769-78.

van de Laar I, Rabelink G, Hochstenbach R, Tuerlings J, Hoogeboom J, Giltay J. Diploid/triploid mosaicism in dysmorphic patients. Clin Genet. 2002;62:376-82.

Van Dyke DL, Weiss L, Roberson JR, Babu VR. The frequency and mutation rate of balanced autossomal rearrangements in man estimated from prenatal genetic studies for advanced maternal age. Am J Hum Genet. 1983;35:301-08.

Verma IC, Saxena R, Lall M, Bijarnia S, Sharma R. Genetic counseling and prenatal diagnosis in India-experience at Sir Ganga Ram Hospital. Indian J Pediatr. 2003;70:293-7.

Warburton D, Kline J, Stein Z, Susser M. Monosomy X: a chromosomal anomaly associated with young maternal age. Lancet. 1980;26;1:167-9.

Yong PJ, Barret IJ, Kalousek DK, Robinson, WP. Clinical aspects, prenatal diagnosis, and pathogenesis of trissomy 16 mosaicism. J Med Genet. 2003;40:175-82.

Zoll B, Wolf J,Lensing-Hebben D, Pruggmayer M, Thorpe B. Trisomy 13 (Patau syndrome) with an 11-year survival. Clin Genet.1993;43:46-50.

Zollino M, Di Stefano C, Zambino G, Mastroiacovo P, Wright TJ, Sorge G, Selicorni A, Tenconi R, Zappalà, Battaglia A, Di Rocco M, Palka G, Pallotta R, Altherr MR,Neri G. Genotype-Phenotype correlations and clinical diagnostic criteria in Wolf-Hirschhorn syndrome. Am J Med Genet. 2000;94:254-61. 